\title{
Requirements of Data Acquisition and Analysis for Condensed Matter Studies at the Weapons Neutron Research/ Proton Storage Ring Facility
}

M. W. Johnson*

J. A. Goldstone

A. D. Taylor*

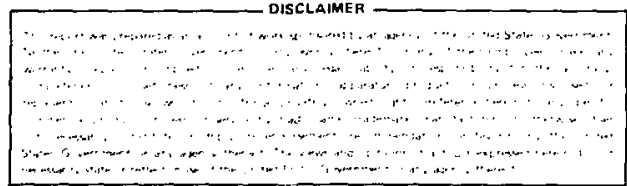

-Borrowed Personnel. Rutherford Appleton Laboratory. Chilton. Didcot, Oxtordshire OX $1100 X$, UNITED KINGDOM.

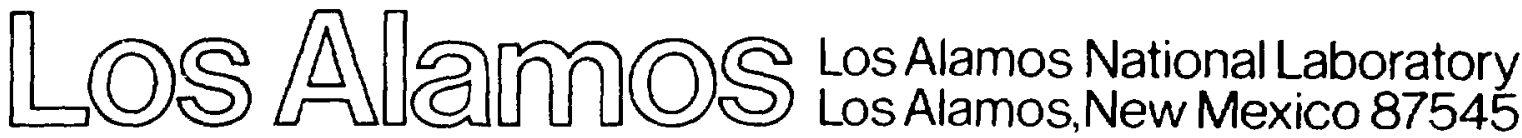




\section{CONTENTS}

ABSTRACT $\ldots \ldots \ldots \ldots \ldots \ldots \ldots$

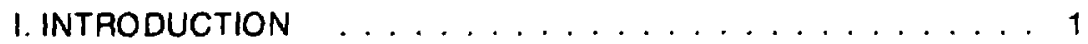

II. SOURCE DEFINITIONS ................. 2

III. THE INSTRUMENT SUITE 1985-1990 . . . . . . . . . . . 4

IV. DATA CAPTURE ELECTRONICS .................. 11

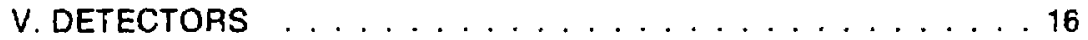

VI. DATA CAPTURE ELECTRONICS . . . . . . . . . 17

VII. THE USER INTERFACE: REQUIREMENTS . . . . . . . . . 19

VIII. THE USER INTERFACE: HARDWARE $\ldots \ldots . \ldots . \ldots 24$

IX. THE USER INTERFACE: SOFTWARE . . . . . . . . . 25

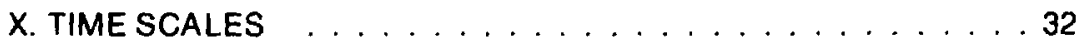

ACKNOWLEDGMENTS $\ldots \ldots \ldots . \ldots \ldots$

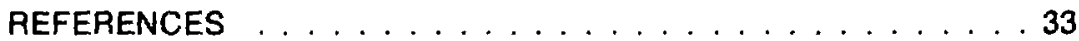




\title{
REQUIREMENTS OF DATA ACQUISITION AND ANALYSIS FOR CONDENSED MATTER STUDIES AT THE WEAPONS NEUTRON RESEARCHI PROTON STORAGE RING FACILITY
}

by

M. W. Johnson, J. A. Goldstone, and A. D. Taylor

\begin{abstract}
With the completion of the proton storage ring (PSR) in 1985, the subsequent increase in neutron flux, and the continuing improvement in neutron scattering instruments, a significant improvement in data acquisition and data analysis capabilities will be required. A brief account of the neutron source is given together with the associated neutron scattering instruments. Based on current technology and operating instruments, a projection for 1985-90 of the neutron scattering instruments and their main parameters are given. From the expected data rates and the projected instruments, the size of data storage is estimated and the user requirements are developed. General requirements are outlined with specific requirements in user hardware and software stated. A project time scale to complete the data acquisition and analysis system by 1985 is given.
\end{abstract}

\section{INTRODUCTION}

A proton storage ring (PSR) will be added to the weapons neutron research (WNR) pulsed neutron source at the Los Alamos Meson Physics Facility in 1985. The PSR will increase the time-averaged neutron flux 25 times and the accompanying change in the repetition rate, from $120 \mathrm{~Hz}$ to $12 \mathrm{~Hz}$, will increase the instantaneous neutron flux 250 times.

The increase in neutron production together with the improvements planned for the neutron scattering instruments requires a commensurate improvement in the fast data capture electronics and real-time data analysis provided for the neutron scattering instruments.

This report is an initial definition of the data acquisition and computing requirements for the PSR. No description of the source has been given as this is available elsewhere (Ref. 1), although the main parameters of the system have been listed to show assumptions that have been made concerning source strength.

The requirements of the system, data capture and interface presented to the user, are defined. They could be incorporated in a larger request for quotation document when possible suppliers are being sought. For this reason we have not attempted to describe specific manufacturers' hardware or software that might be used in the data acquisition system. 


\section{SOURCE DEFINITIONS}

The overall layout of the WNR neutron source planned for early 1985 is shown in Fig. 11-1. This illustrates the three main components of the facility: the PSR, the highcurrent target, and the experimental areas containing the neutron scattering instruments. The high-current target exists, the neutron instruments are at varying stages of development, and PSR construction has just begun.

To estimate future neutron flux levels we assumed that the proton beam delivered to the target has the characteristics listed below.

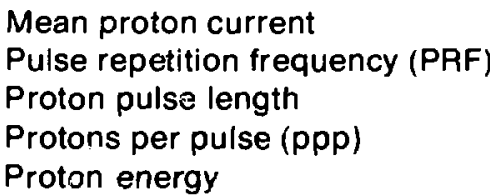

$100 \mu \mathrm{A}$

$12 \mathrm{~Hz}$

$270 \mathrm{~ns}$

$5.2 \times 10^{13}$

$800 \mathrm{MeV}$

When $800-\mathrm{MeV}$ protons impinge on a tungsten target they produce approximately 15 neutrons per proton with a primary energy spectrum ranging from kiloelectron volts to hundreds of million electron volts. To procuce short pulses of neutrons $(1-100 \mu \mathrm{s})$ in the thermal and epithermal region $(0.01-10 \mathrm{eV})$, the target is surrounded by small hydrogenous moderators. A possible moderator configuration is shown in Fig. II-2, together with the numbered flight paths (FP).

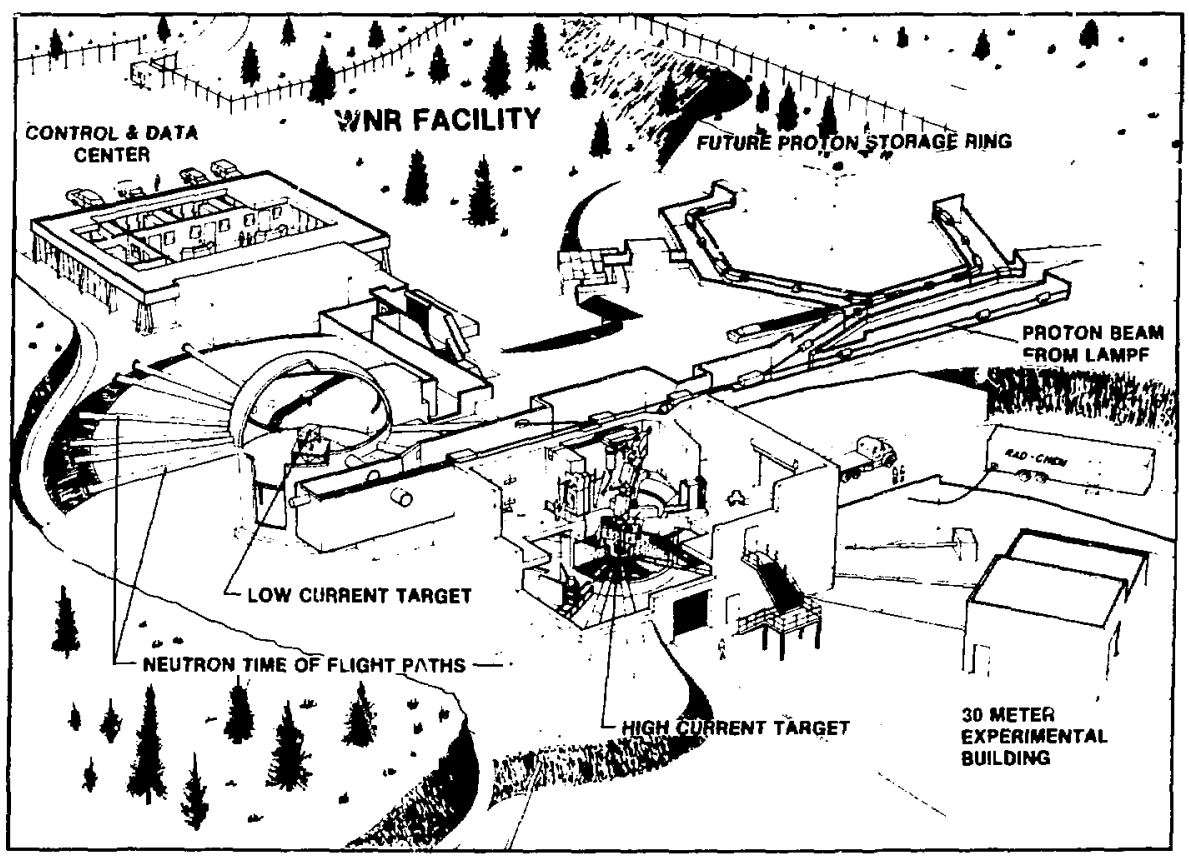

Fig. II-1. Layout of the WNR/PSR facility. Condensed matter research uses the high-current target and several of the horizontal time-of-flight paths. 


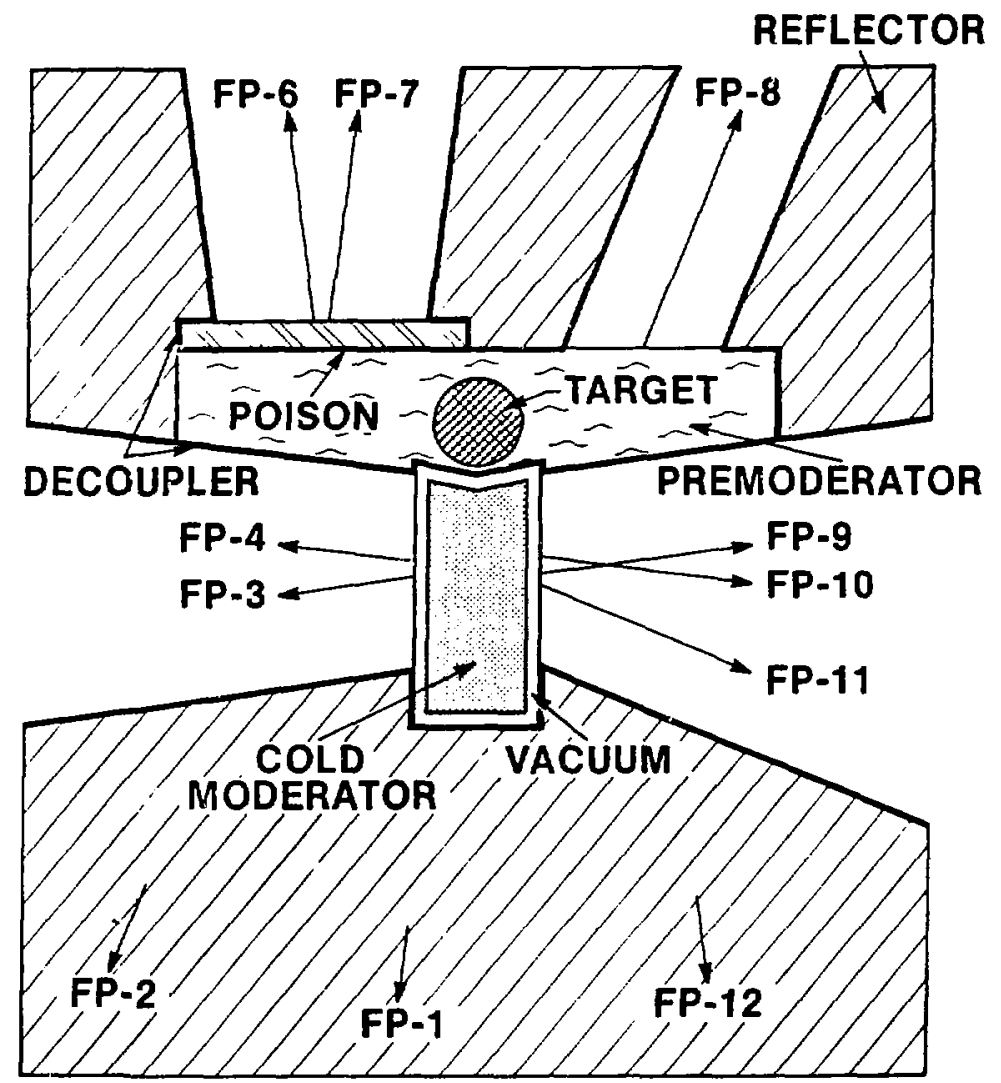

Fig. II-2. A possible target-moderator configuration. The neutron spectrum needs of the instrument zan be met by viewing various moderators.

Different groups of instruments require different neutron flux-time distribution characteristics. These are realized by providing three types of moderator that have different dimensions, compositions, and temperatures. The expected coupling parameters (thermal neutrons produced per proton) and the corresponding thermal neutron fluxes for the moderators shown in Fig. II-2 are given in Table ||$-\mid$.

TABLE II-I. Possible Moderators and Their Coupling Parameters

\begin{tabular}{|c|c|c|}
\hline Moderator & $\begin{array}{c}\text { Neutron/Proton } \\
\text { Coupling } \\
n / e V \cdot s r \cdot p \\
\text { at } E=1 \mathrm{eV}\end{array}$ & $\begin{array}{c}\text { Neutron Flux } \\
E=1 \mathrm{eV} \\
\text { n/eV.sr.s }\end{array}$ \\
\hline $\begin{array}{l}1 \text { in. } \\
1 / 2 \text { in. } \\
\text { cold }\end{array}$ & $\begin{array}{l}5 \because 10^{-3} \\
5 \div 10^{-} \\
4 \times 10^{-3}\end{array}$ & $\begin{array}{l}3.1 \times 10^{12} \\
3.1 \times 10^{12} \\
2.5 \times 10^{12}\end{array}$ \\
\hline
\end{tabular}


The expected variation of neutron flux as a function of energy is shown in Fig. II-3. Data acquisition rates for the PSR instruments have been calculated using Table $\|-1$ and Fig. I1-3.

\section{THE INSTRUMENT SUITE 1985-1990}

The experimental area is shown in Fig. III-1 with the neutron flight paths indicated. The present thermal neutron scattering instruments are listed with their flight path number.

A continuous program of instrument enhancement is planned for the next few years so that by the mid-through-late 1980 s a suite of eight fully engineered instruments will be in operation. It is possible that in the future a new target station may be built with up to 20 beam lines.

To plan the medium-to-long term (1985-90) computing needs it would seem appropriate to assume a set of eight instruments as the target system. This number can be accommodated easily on the existing beam lines and is large enough to be representative of the computing needs of a (eventually) larger set of instruments. The suggested set of eight instruments is given in Table III-I (Ref. 2).

Figures III-2 through III-9 present characteristics of the instruments necessary to define the data acquisition rates. These parameters must be regarded as tentative because detailed plans of the instruments have not been developed.

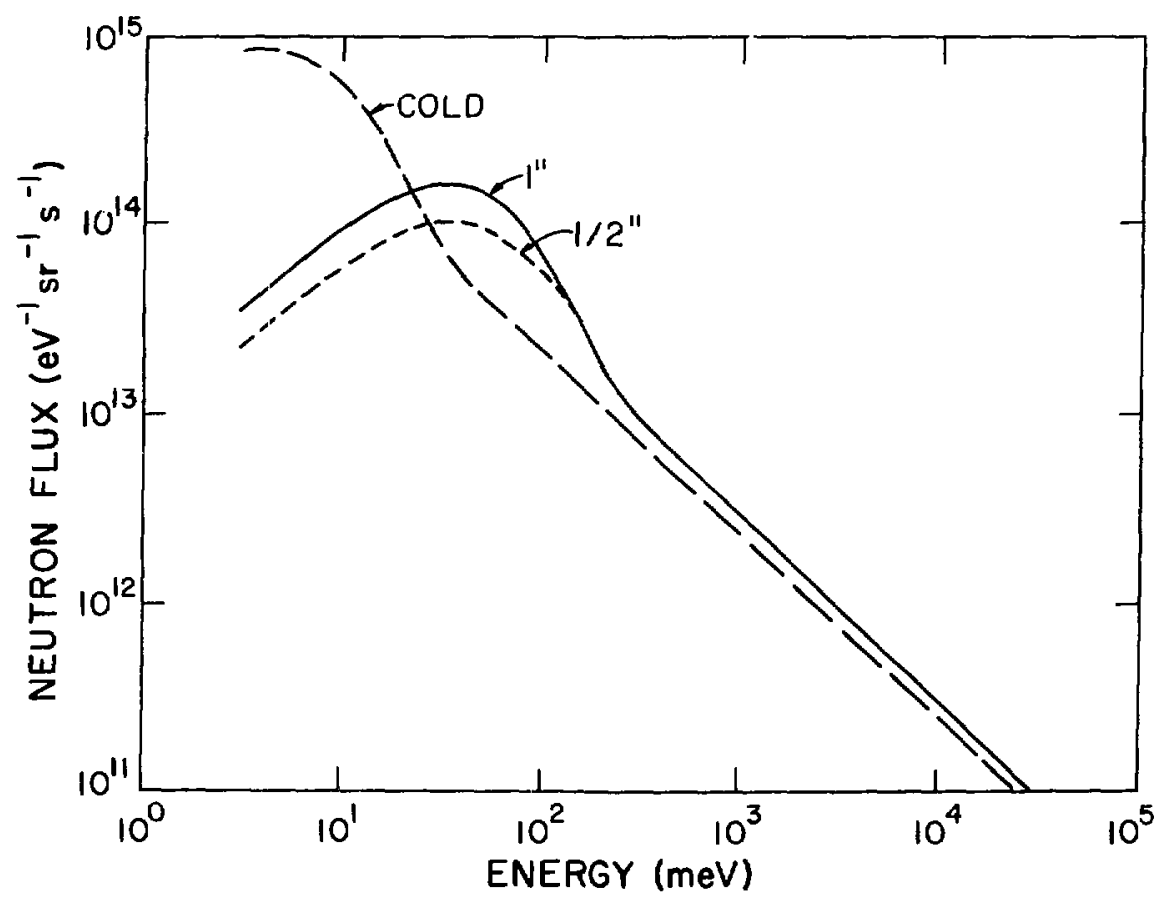

Fig. If-3. The variation of neutron flux as a function of energy is shown for the three moderators described in Table II-I. 


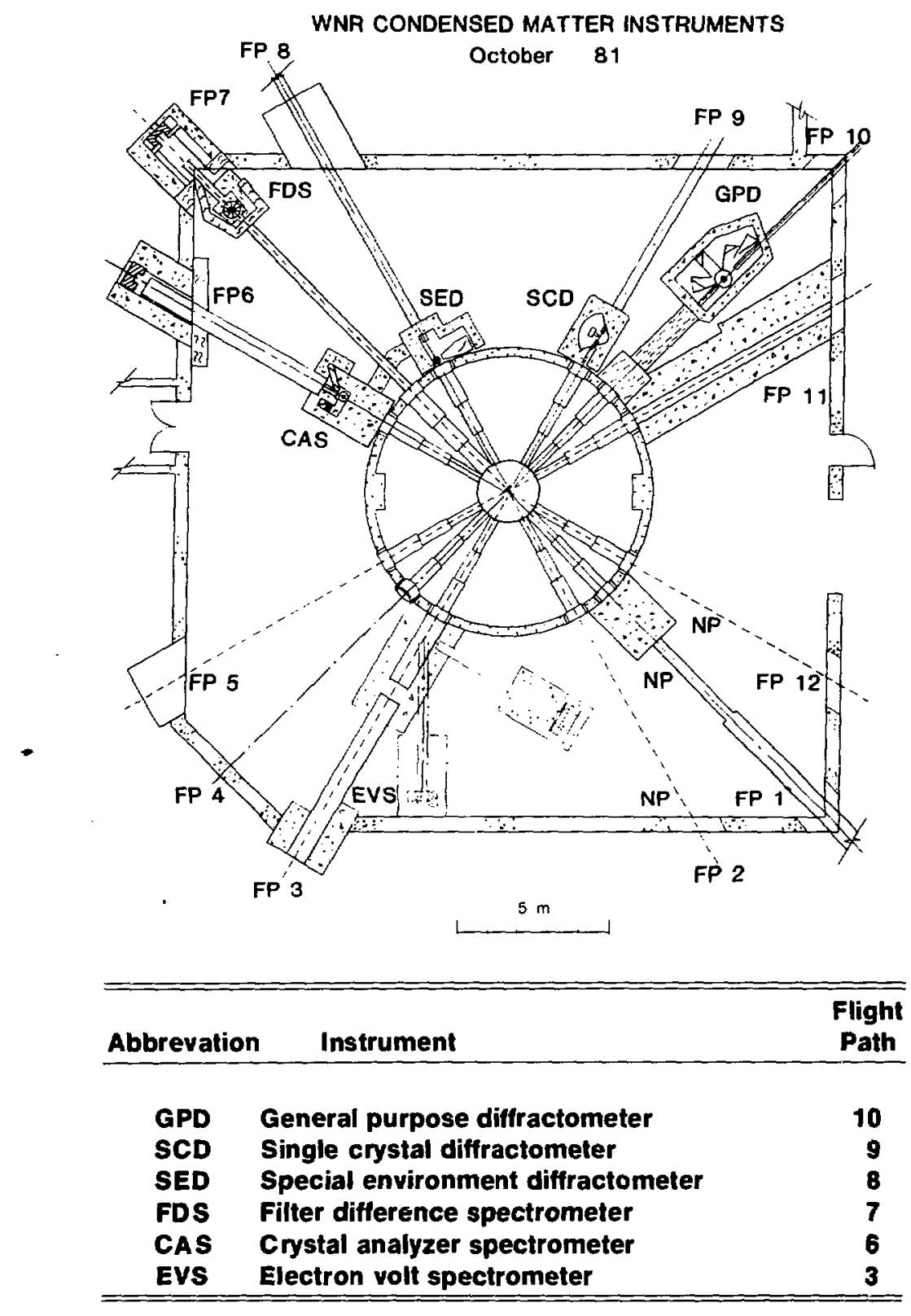

Fig. III-1. The high-current target area and instrument layout is shown as of October 1981. Nuclear Physics (NP) will use the very long flight paths 1, 2, and 12. Flight path 4 is directed toward the low-current target area. All other flight paths are available for condensed matter research. 
TABLE III-I. Planned Instruments and Flight Path Assignments for the WNR/PSR Facility

\begin{tabular}{clr} 
Abbrevation & Name & $\begin{array}{c}\text { Flight } \\
\text { Path }\end{array}$ \\
\hline CaS & Constant-a spectrometer & 3 \\
SCD & Single crystal diffractometer & 6 \\
FDS & Filter difference spectrometer & 7 \\
CS & Chopper spectrometer & 8 \\
BS & Backscattering spectrometer & 9 \\
SANS & Small angle neutron scattering & 10 \\
HRPD & High-resolution powder diffractometer & 11 \\
GPD & General purpose diffractometer & 11 \\
\hline
\end{tabular}

\section{SINGLE CRYSTAL DIFFRACTOMETER}

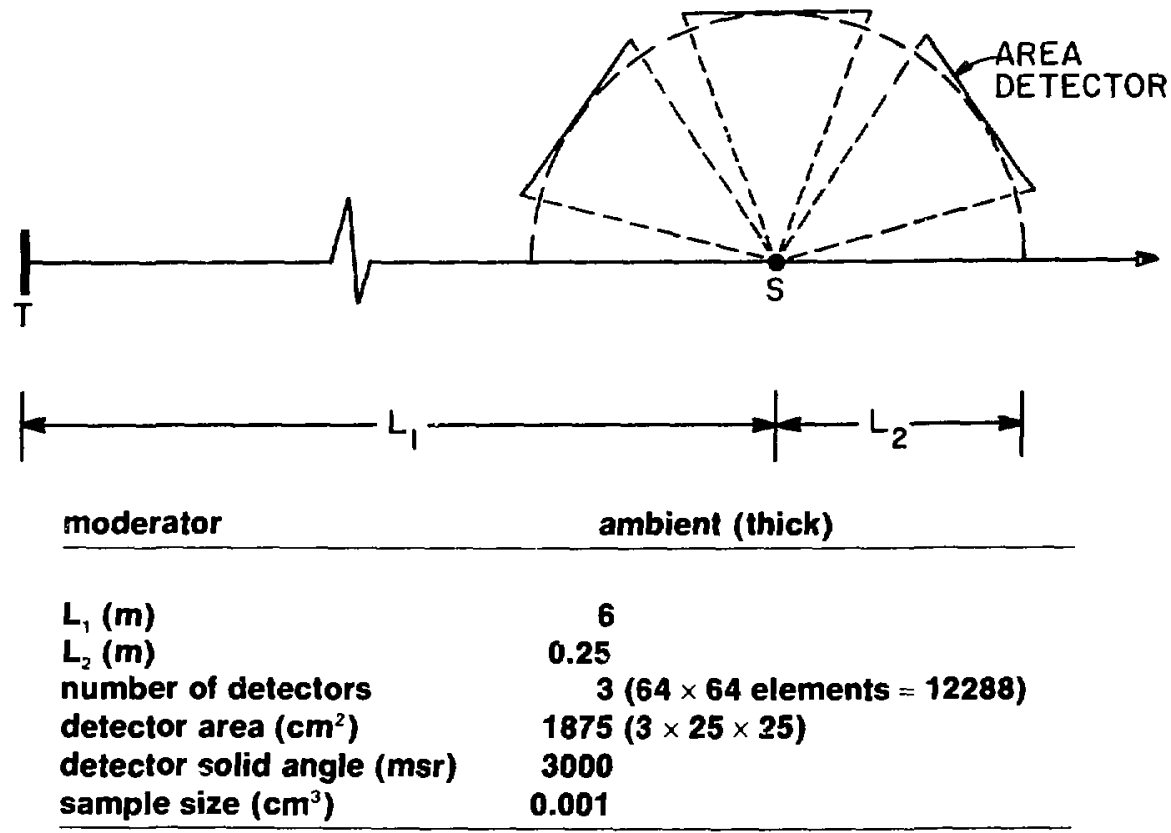

Fig. III-2. A schematic of the single crystal diffractometer and important instrument parameters. 
FILTER DIFFERENCE SPECTROMETEF:

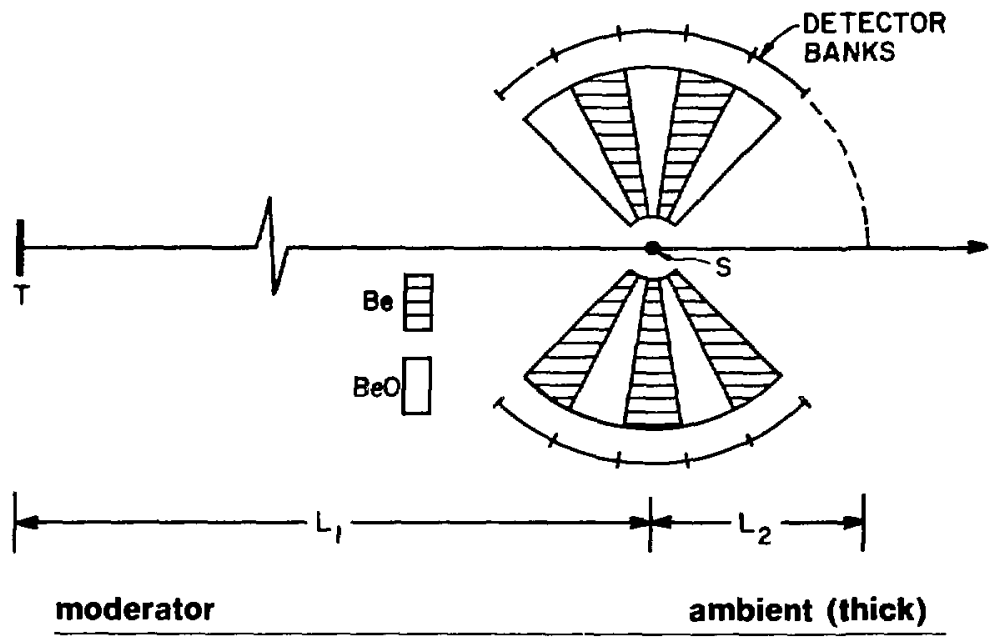

$L,(m)$

13

$L_{2}(m)$

0.28

number of detectors

60

detector area ( $\left.\mathrm{Cl}_{2}^{2}{ }^{2}\right)$

900

detector solid angle (msr)

870

sample size $\left(\mathrm{cm}^{3}\right)$

5

Fig. III-3. A schematic of the filter difference spectrometer and important instrument parameters.

\section{GENERAL PURPOSE DIFFRACTOMETER}

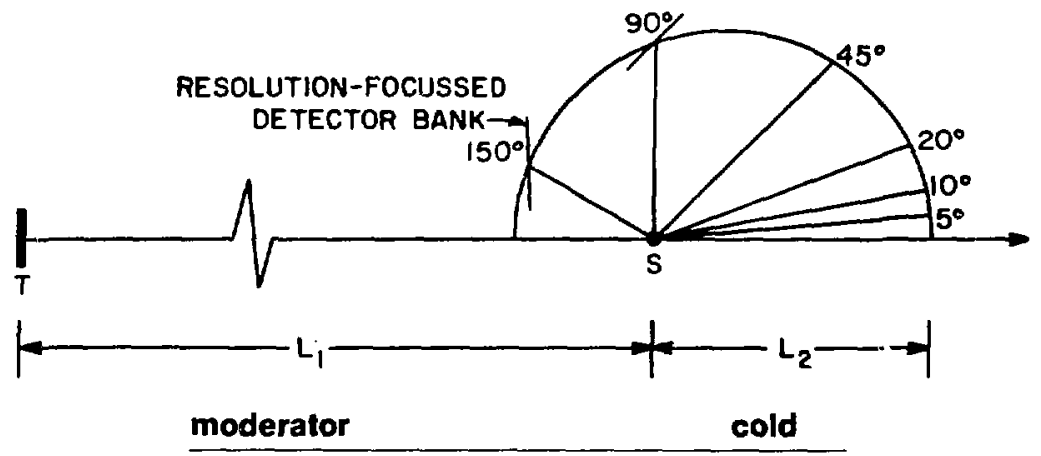
L, (m)
10
$L_{2}$ (m)
1-2
number of detectors
120
detector area $\left(\mathrm{cm}^{2}\right)$
1800
detector solid angle (msr)
120
sample size $\left(\mathrm{cm}^{3}\right)$
5

Fig. III-4. A schematic of the general purpose diffractometer and important instrument parameters. 


\section{HIGH-RESOLUTION POWDER DIFFRACTOMETER}
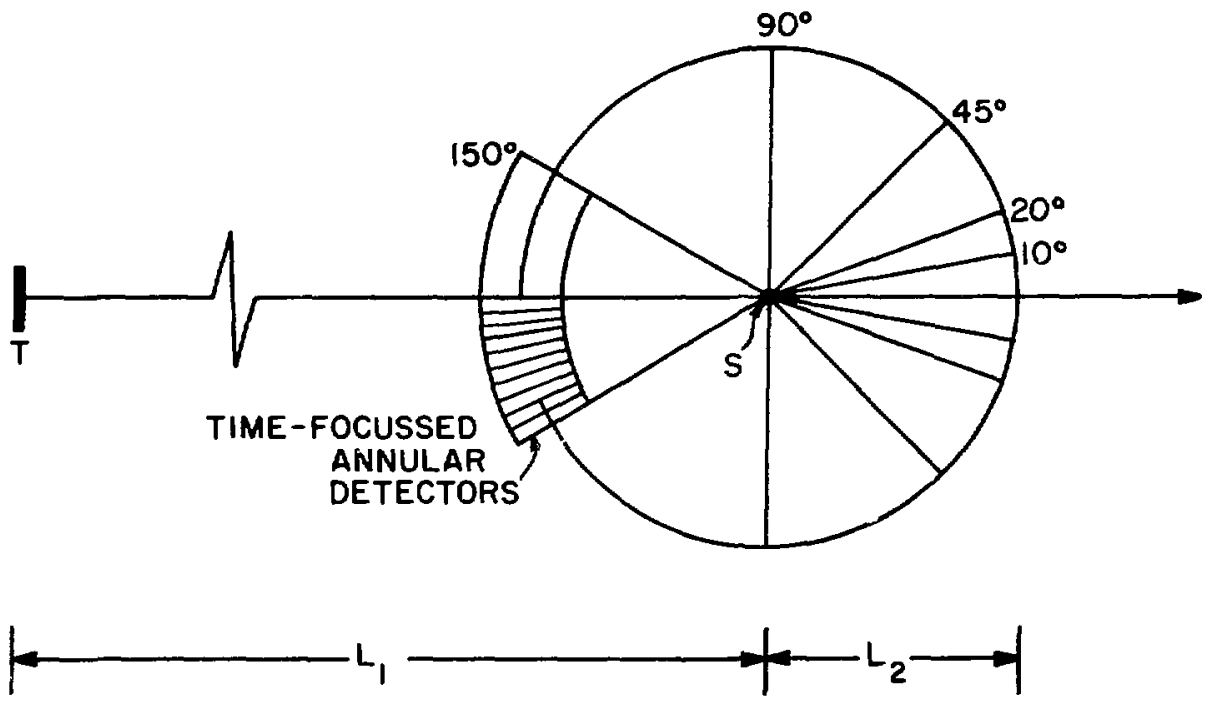

moderator

cold

\begin{tabular}{lr}
$L_{1}(m)$ & 30 \\
$L_{2}(n)$ & 2 \\
number of detectors & 240 \\
detector area $\left(\mathrm{cm}^{2}\right)$ & 3600 \\
detector solid angle $(\mathrm{msr})$ & 90 \\
sample size $\left(\mathrm{cm}^{3}\right)$ & 5 \\
\hline
\end{tabular}

Fig. III-5. A schematic of the high-resolution powder diffractometer and important instrument parameters. 


\section{CONSTANT-Q SPECTROMETER}
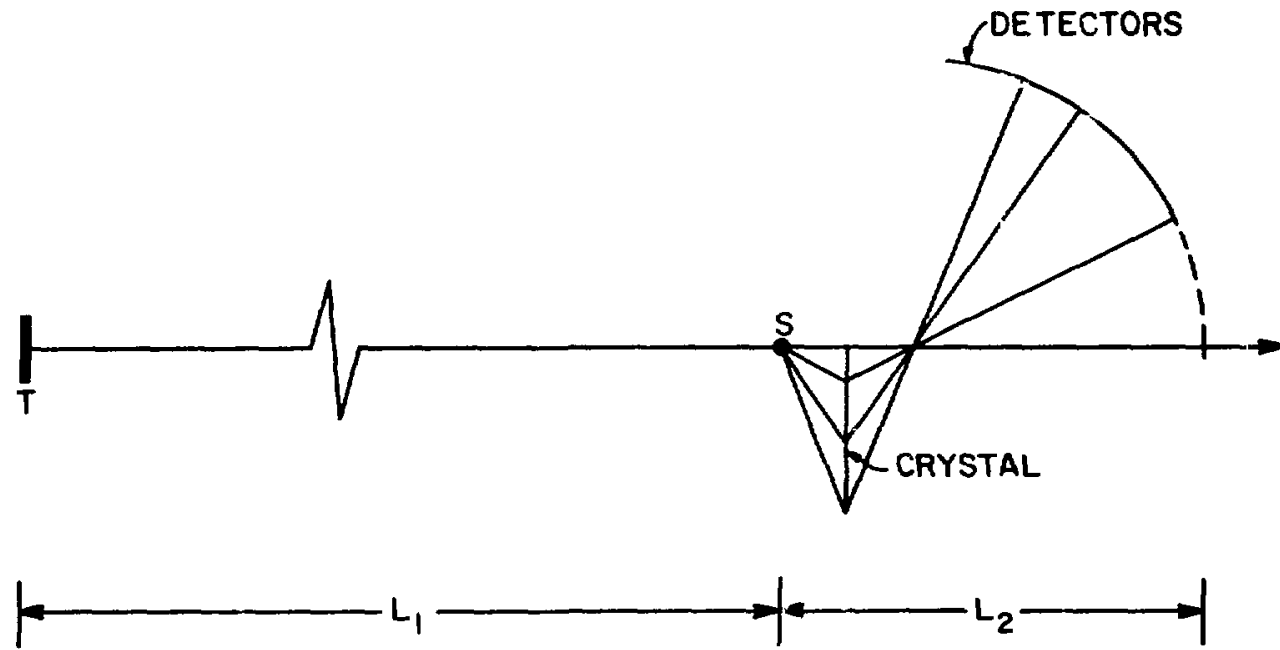

moderator

cold

$L_{1}(\mathbf{m})$

$L_{2}(\mathrm{~m})$

number of detectors

detector areas $\left(\mathrm{cm}^{2}\right)$

dete stor solid angle (msr)

sample size $\left(\mathrm{cm}^{3}\right)$
10

$1.8-2.5$

128

1920

85

5

Fig. III-6. A schematic of the constant-Q spectrometer and important instrument parameters. 


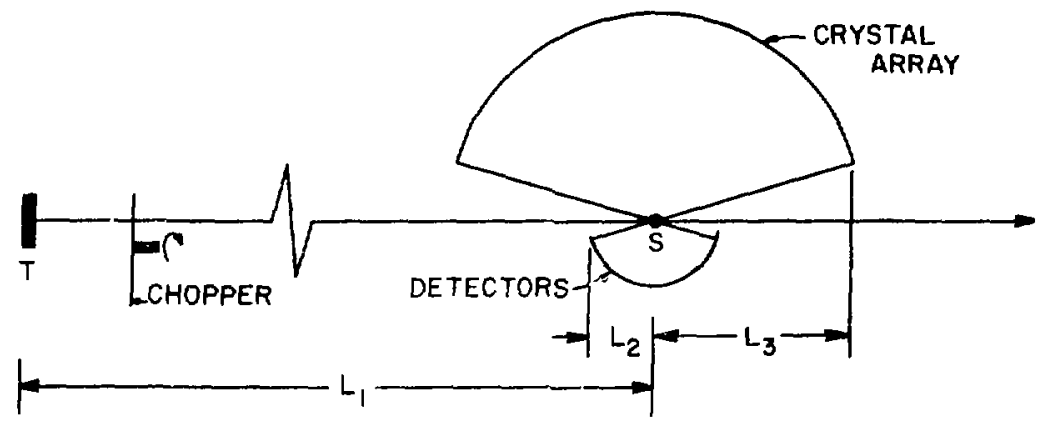

\begin{tabular}{lr} 
moderator & cold \\
\hline & \\
$L_{1}(m)$ & 40 \\
$L_{2}(m)$ & 0.5 \\
$L_{3}(m)$ & 1.0 \\
number of detectors & 128 \\
detector area $\left(\mathrm{cm}^{2}\right)$ & 1920 \\
detector solid angle (msr) & 770 \\
sample size $\left(\mathrm{cm}^{3}\right)$ & 5 \\
\hline
\end{tabular}

Fig. IIt-7. A schematic of the backscattering spectrometer and important instrument parameters.

\section{SMALL ANGLE NEUTRON SCATTERING}
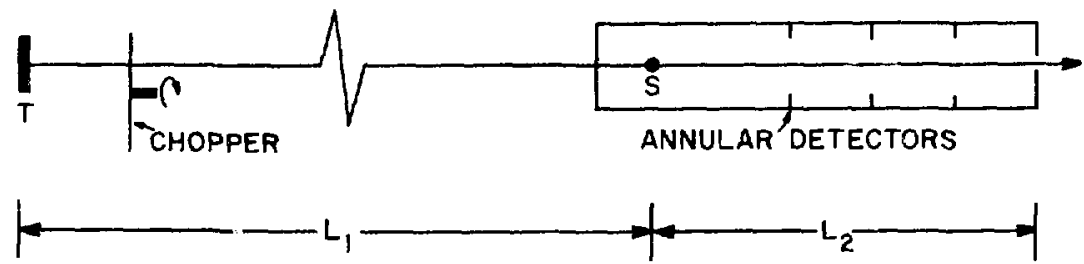

\begin{tabular}{lr} 
moderator & cold \\
\hline$L_{1}(\mathrm{~m})$ & 10 \\
$L_{2}(\mathrm{~m})$ & $1-10$ \\
number of detectors & 256 \\
detecior area $\left(\mathrm{cm}^{2}\right)$ & 3840 \\
detector solid angle (msr) & 96 \\
sampie size $\left(\mathrm{cm}^{3}\right)$ & 5 \\
\hline
\end{tabular}

Fig. III-8. A schematir of the small angle neutron scattering spectrometer and important instrument paranieters. 


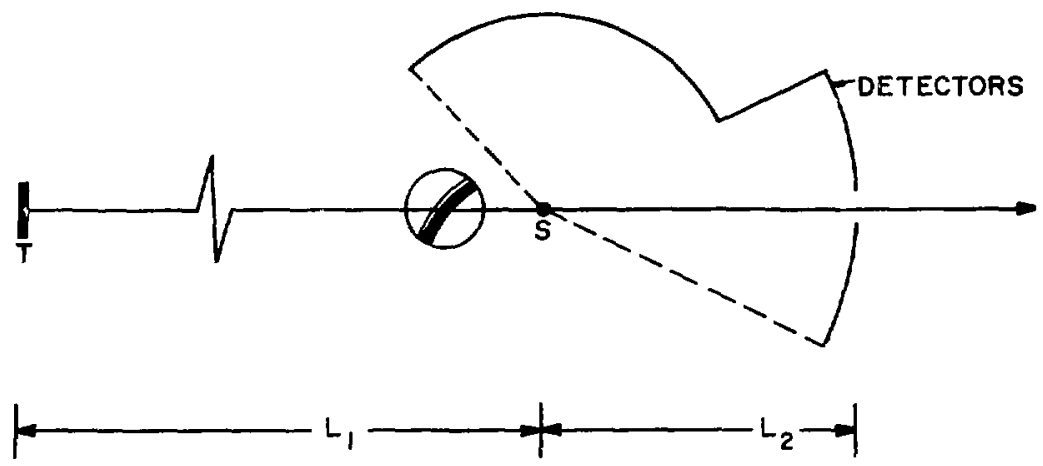

\begin{tabular}{lc} 
moderator & ambient (thin) \\
\hline & 12 \\
$L_{1}(\mathrm{~m})$ & $1-2$ \\
$L_{2}(\mathrm{~m})$ & 512 \\
number of detectors & 7680 \\
detector area $\left(\mathrm{cm}^{2}\right)$ & 192 \\
detector solid angle (msr) & 5 \\
sample size $\left(\mathrm{cm}^{3}\right)$ & \\
\hline
\end{tabular}

Fig. III-9. A schematic of the chopper spectrometer and important instrument parameters.

\section{EXPECTED DATA RATES}

We used source definitions in Sec. II together with the instrument descriptions of Sec. III to estimate the data rate- expected when PSR becomes operational.

Whenever possible we estimi...d the rates for PSR instruinents (GPD, HRPD, SCD, FDS) from the performance of existing instruments in operation at WNR (for example, GPD, SCD, IDS).

In other cases (CQS, SANS, BS, CS), we scaled the estimate made for similar spallation neutron source instruments at the Rutherford Appleton Laboratory.

Neutron detection rates will vary among experiments performed on the same instrument. The rates quoted are for experimental conditions producing maximal data rates.

The detection rates are given in Table IV-I and the definition of the row headings are given below. Table IV-I characterizes the time variability of the neutron detection problem. The detection raies quoted are for the total detector system.

All detectors record a time-of-flight spectrum by assigning a detected neutron to a particular time channel (see Fig. IV-1). The time channels may not be of constant width, but all detectors share the same time channels (that is, a single clock may be used to encode all neutrons detected). The form of a time-of-flight spectrum is shown in Fig. IV-1. Because of the value of the PRF used $(12 \mathrm{~Hz})$, all of the spectrum may be recorded within the frame. (The frame is the period between sucessive proton pulses hitting the target.) 
TABLE IV-I. Detection Rates Expected During WNR/PSR Operation

SCD FDS $\underset{\text { (powder) }}{\text { GPD }} \begin{gathered}\text { (liquid) } \\ \text { (pow HAPD } \text { CQS }^{\mathrm{a}} \text { ES SANS CS }\end{gathered}$

\begin{tabular}{|c|c|c|c|c|c|c|c|c|c|}
\hline $\begin{array}{l}C R(n / s) \\
F C(n) \\
m(n / \mu s)\end{array}$ & $\begin{array}{r}24000 \\
2000 \\
0.4\end{array}$ & $\begin{array}{r}10000 \\
900 \\
0.2\end{array}$ & $\begin{array}{r}450000 \\
36000 \\
3.6\end{array}$ & $\begin{array}{r}96000 \\
8000 \\
0.8\end{array}$ & $\begin{array}{r}36000 \\
3000 \\
0.1\end{array}$ & $\begin{array}{r}12000 \\
1000 \\
0.2\end{array}$ & $\begin{array}{r}12000 \\
1000 \\
0.02\end{array}$ & $\begin{array}{r}48000 \\
4000 \\
0.2\end{array}$ & $\begin{array}{r}2.000 \\
160 \\
.04\end{array}$ \\
\hline$r_{1}(n / \mu / s)$ & 5 & 1 & 45 & 2.4 & 3.8 & 2 & 5 & 2 & 0.5 \\
\hline$r_{10}(n / \mu / s)$ & 5 & 1 & 45 & 2.4 & 3.8 & 2 & 5 & 2 & 0.5 \\
\hline$r_{100}(n / \mu s)$ & 3 & 1 & 21 & 2.1 & 1 & 0.8 & 3 & 1 & 0.2 \\
\hline$r_{1000}(n / \mu s)$ & 2 & 0.4 & 7.2 & 1.7 & 0.2 & 0.4 & 1 & 0.4 & 0.1 \\
\hline$r_{10000}(n / \mu s)$ & $\cdots$ & $\cdots$ & 3.6 & 0.8 & 0.1 & -.- & 0.1 & 0.3 & -- \\
\hline$t_{1}(\mu s)$ & 400 & 900 & 250 & 250 & 750 & 1000 & 1000 & 12000 & 250 \\
\hline$t_{2}(\mu \mathrm{s})$ & 5400 & 4900 & 10250 & 10250 & 30750 & 6000 & 61000 & 30000 & 4250 \\
\hline DW $(\mu \mathrm{s})$ & 5000 & 4000 & 10000 & 10000 & 30000 & 5000 & 60000 & 18000 & 4000 \\
\hline $\mathbf{n}_{\mathbf{t}}$ & 256 & 1000 & 8000 & 4000 & 16000 & 2000 & 4000 & 512 & 4000 \\
\hline$n_{0}$ & 12288 & 60 & 120 & 120 & 240 & 128 & 128 & 256 & 512 \\
\hline
\end{tabular}

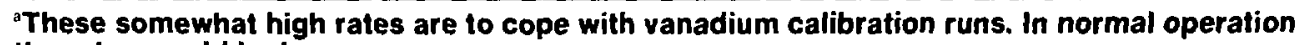
the rates would be lower.

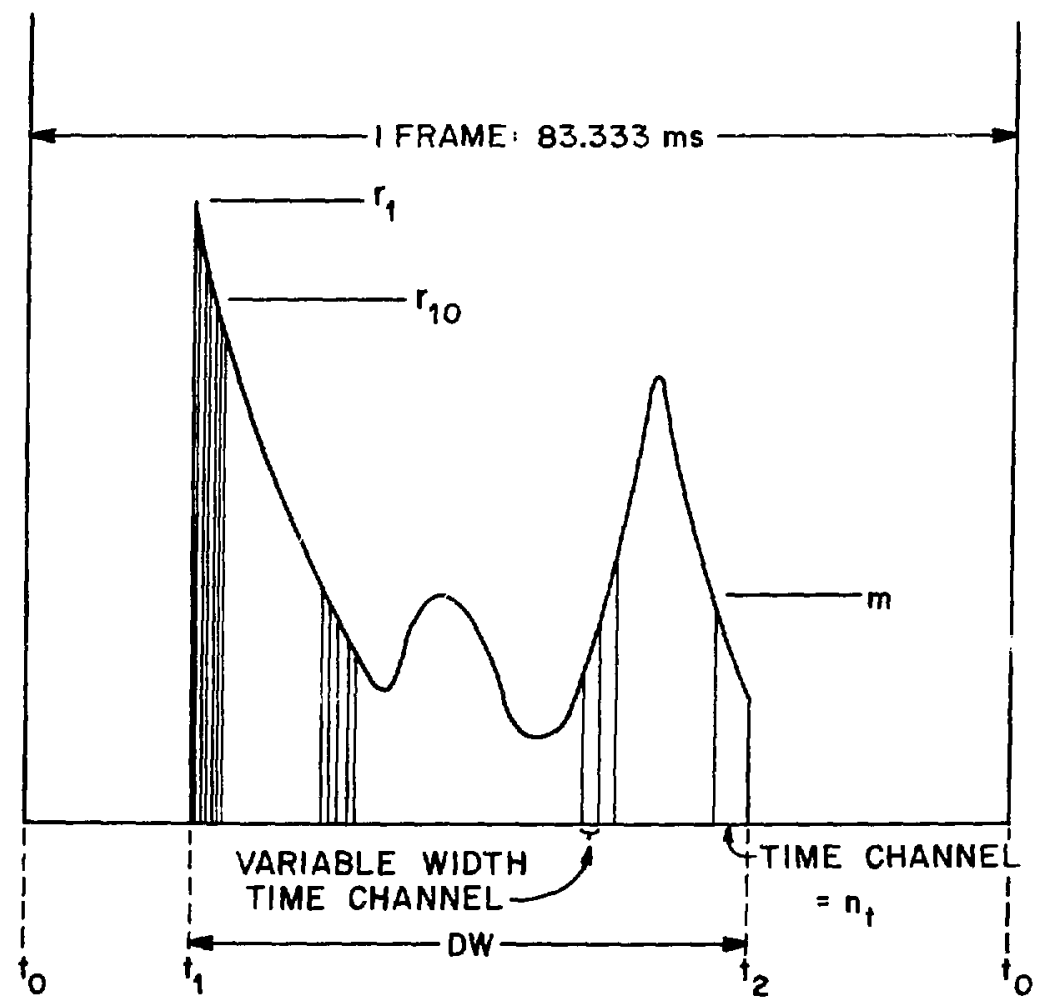

Fig. IV-1. A schematic representation of a collected spectrum in one frame with parameters describing data collection rates. 
To characterize the spectrum that may be recorded, we have used the quantities, $C R, F C, m$, etc., shown in Table IV-I. The definitions of these quantities givan below are illustrated in Fig. IV-1.

Spectrum characteristic definitions are:

$t_{0}$ is the time a proton pulse hits the spallation target.

The frame is the time between two $t_{0}$ 's.

$t_{1}$ is the time at which data ccllection starts.

$t_{2}$ is the time at which data collection ceases.

DW is the data collection window $\left(=t_{2}-t_{1}\right)$.

$n_{t}$ is the maximum number of time channels to be employed.

The frame count (FC) is the number of neutrons arriving between $t_{1}$ and $t_{2}$.

$m$ is the mean count rate during the frame in neutrons per microsecond $(n / \mu s)$.

Hence, $m=F C /\left(t_{2}-t_{1}\right)$.

The overall count rate (CR) is the mean detection rate averaged over many frames. The count rate is expressed in neutrons per second.

Hence, $\mathrm{CR}=12 \times \mathrm{FC}$.

The values $r_{1}, r_{10}, r_{100}, r_{1000}, r_{10000}$ refer to the highest data rates expected over periods of $1 \mu \mathrm{s}, 10 \mu \mathrm{s}, 100 \mu \mathrm{s}$, etc., within the frame.

Figure IV-2 shows the variation of $r_{1}$ with i graphically for the GPD used for powder and liquid samples. Figures IV-3, IV-4, and IV-5 show typicai spectra for a powder sample (GPD), liquid sample (GPD), and an inelastic spectrum (FDS).

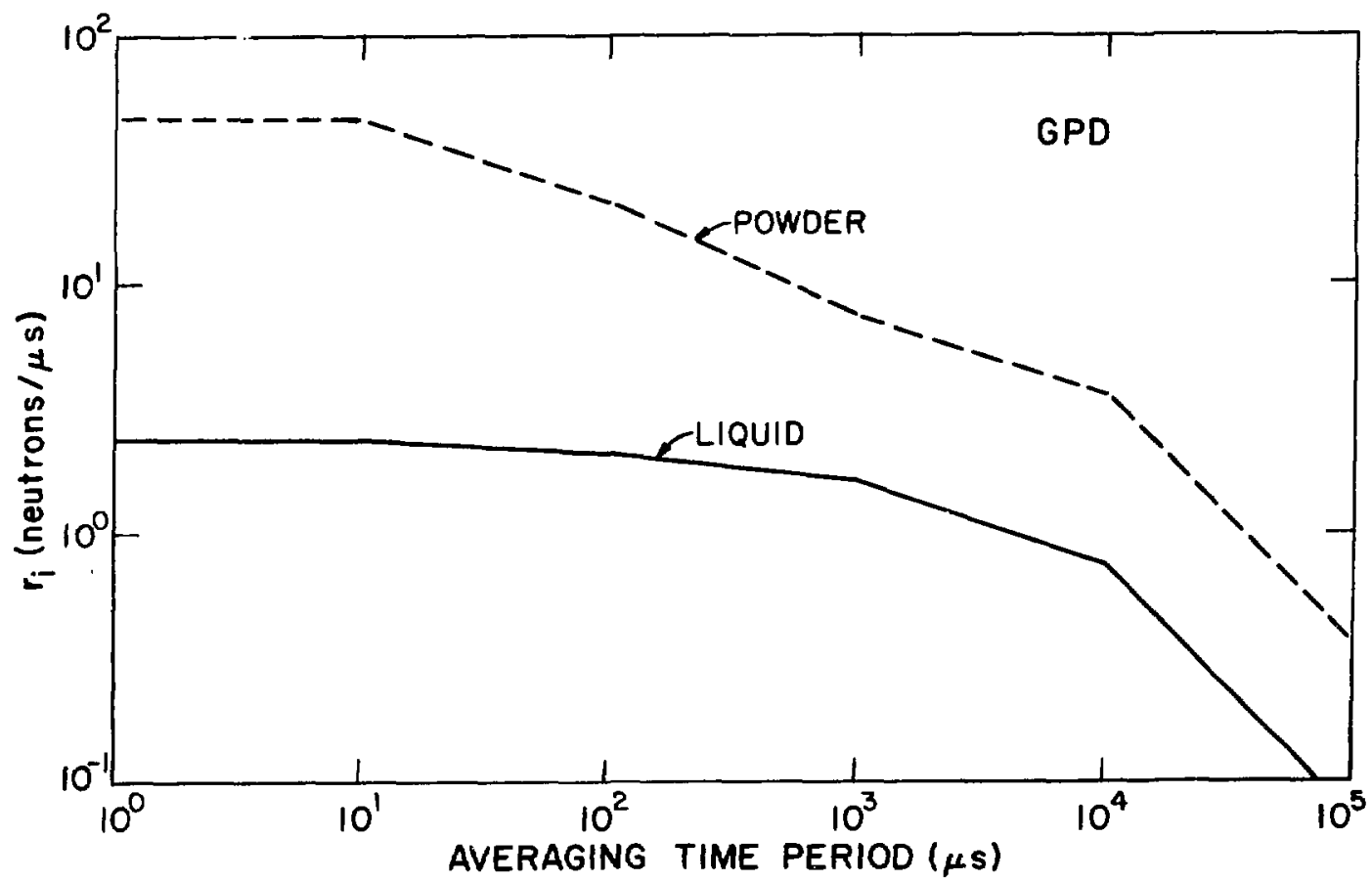

Fig. IV-2. The variation of $r_{1}$ with $i$ for the GPD instrument with a powder sample and a liquid sample. 


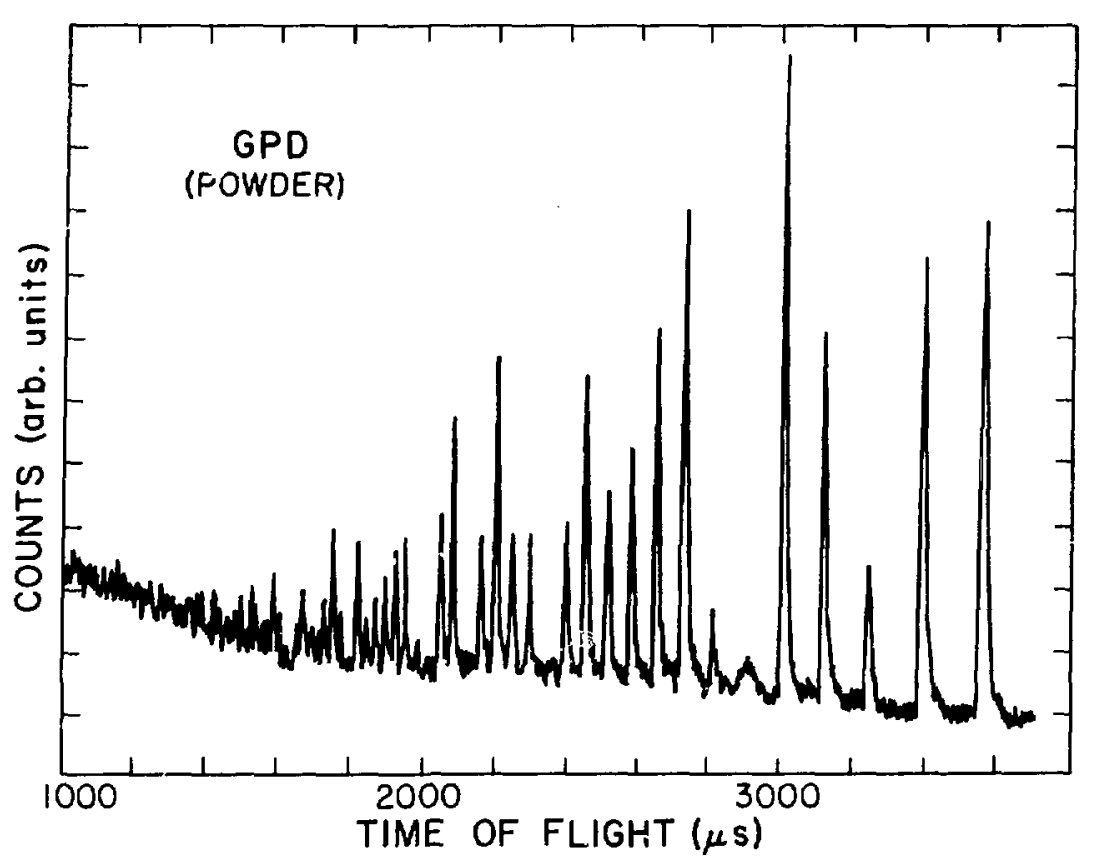

Fig. IV-3. A typical spectrum for a powder sample taken on the GPD instrument.

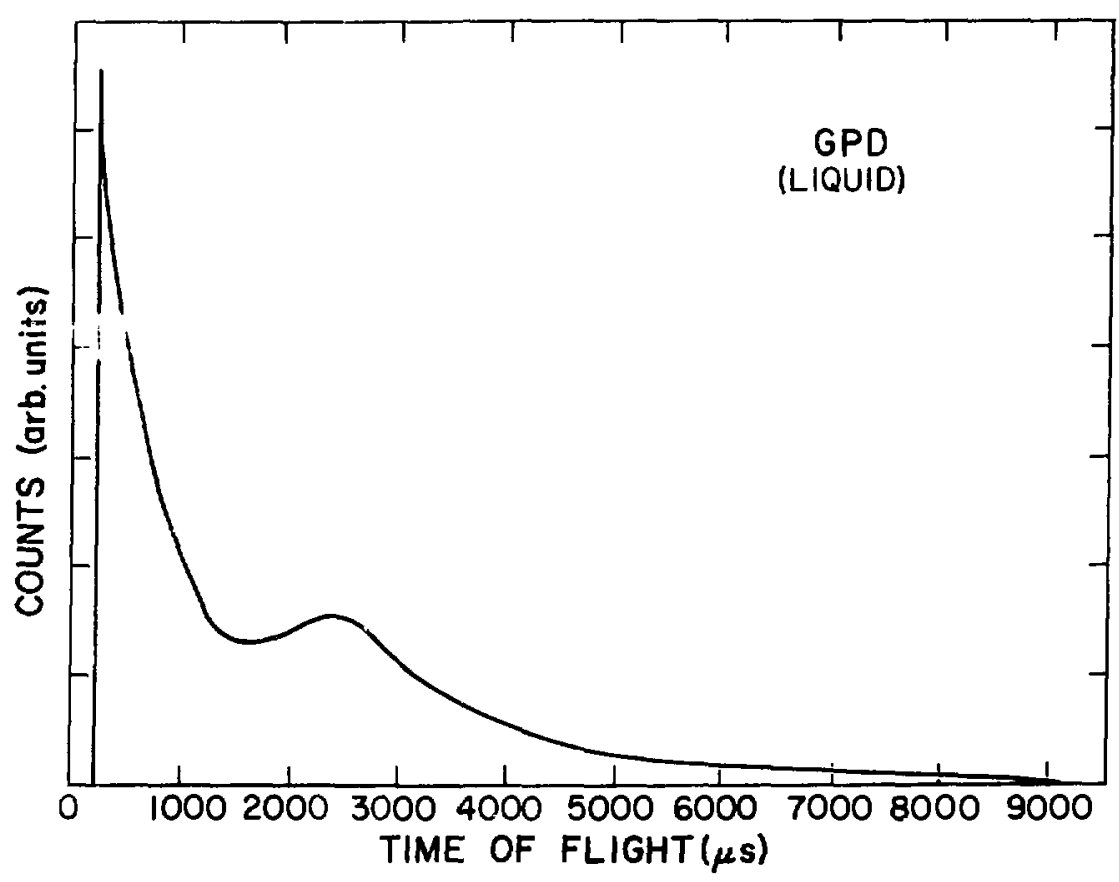

Fig. IV-4. A liquid sample spectrum taken on the GPD instrument. 


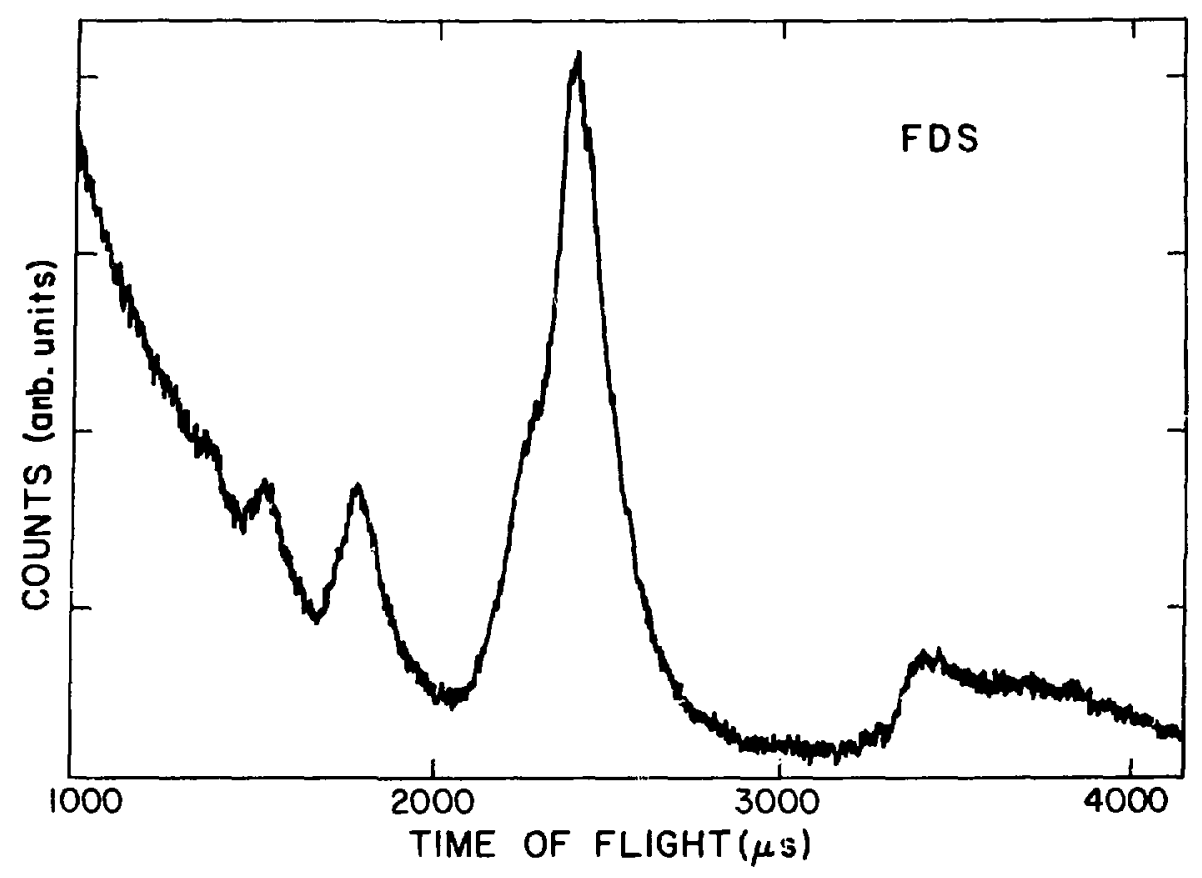

Fig. IV-5. An inelastic spectrum taken on the FDS prior to differencing.

The numbers in Table IV-I refer to the entire detector system. In some instruments where the neutrons are scattered isotropically, the detection rate per detector may be obtained by dividing the rates by the number of detectors $\left(n_{d}\right)$. In other instruments, especially the SCD, the scattering is far from isotropic and the detected neutrons are concentrated in only a fraction of the detector elements. To quantify this effect, Table IV-II contains a column marked spatial anistropy; the number the average rate per detector should be multiplied by to give the rates found in the brightest detectors. Thus an anistropy of one implies that the scattering is isotropic.

\begin{tabular}{|c|c|c|}
\hline Instrument & Number of Detectors & Spatial Anisotropy \\
\hline SCD & 12288 & 20 \\
\hline FDS & 60 & 2 \\
\hline GPD (powder) & 120 & 5 \\
\hline GPD (liquid) & 120 & 2 \\
\hline HRPD & 240 & 3 \\
\hline cas & 128 & 2 \\
\hline BS & 128 & 2 \\
\hline SANS & 256 & 5 \\
\hline CS & 512 & 2 \\
\hline
\end{tabular}




\section{DETECTORS}

For the purpose of the preceding calculations, all instruments (except the SCD) have been assumed to use detectors with an effective detection area of $1 \times 15 \mathrm{~cm}$. The SCD uses three area detectors providing $64 \times 64$ elements each. The average detection rate for a single detector is sbtained ky simply dividing the rate shown in Table IV-I by the number of detectors. (It has been assumed in most cases that the detectors are equidistant from the sample.) Because it is important that the detectors should not cause any undue dead-time correction, we have listed the average peak detection rate $r$, per detector for each instrument (Table $V$-I). The fraction of lost counts $f$ resulting from the detector dead time is given by

$$
f=\frac{\Delta r_{1}}{1+\Delta r_{1}}
$$

where $\Delta$ is the dead time.

For gas detectors the value of $\Delta$ can vary considerably depending on the orientation of the charged particle track to the anode wire. For $\mathrm{BF}_{3}$ detectors a study at the institut Laue-Langevin (Ref. 3 ) has shown the dead time to be $\sim 2 \mu \mathrm{s}$. If specially constructed* ${ }^{3} \mathrm{He}$ detectors may be made to run faster and in this case the dead time can be reduced to $\sim 1 \mu \mathrm{s}$.

Scintillator detectors are inherently faster with a dead time of $\sim 100 \mathrm{~ns}$. If combinatorial techniques are used to encode a large number of scintillator elements with a smaller number of photomultipliers, the dead time does nui refer to individual elements, but to some large fraction of the entire group.

The fraction of lost counts $f$ is shown in Table $V-I$ when $\Delta$ takes the values $2 \mu \mathrm{s}, 1 \mu \mathrm{s}$, and $0.1 \mu \mathrm{s}$. By using the faster ${ }^{3} \mathrm{He}$ detectors, the dead-time losses for both the SCD and GPD (used for powder samples) are still unacceptably high. For these two instruments the use of scintillator detectors should be seriously considered to obtain tolerable dead-time corrections.

"This information was supplied by $\mathrm{H}$. Wroe, Rutherford Appleton Laboratory, Chilton, Didcot, Oxfordshire OX11 0QX, United Kingdom.

TABLE V-I. Peak Detection Rate per Detector for Each Instrument

Fraction of Lost Neutrons,

\begin{tabular}{|c|c|c|c|c|c|c|}
\hline Instrument & $n_{d}$ & $\mathbf{r}_{1}$ & $r_{1} /$ Detector & $\Delta=2 \mu \mathrm{S}$ & $\Delta=1 \mu \mathrm{s}$ & $\Delta=0.1 \mu \mathrm{s}$ \\
\hline SCD & 3 & 5 & 1.7 & 0.77 & 0.63 & 0.14 \\
\hline FDS & 60 & 1 & 0.02 & 0.04 & 0.02 & 0.002 \\
\hline GPD (p) & 120 & 45 & 0.4 & 0.44 & 0.29 & 0.04 \\
\hline GPD (I) & 120 & 2.4 & 0.02 & 0.04 & 0.02 & 0.002 \\
\hline HRDP & 240 & 3.8 & 0.02 & 0.04 & 0.02 & 0.002 \\
\hline cas & 128 & 2 & 0.02 & 0.04 & 0.02 & 0.002 \\
\hline BS & 128 & 5 & 0.04 & 0.07 & 0.04 & 0.004 \\
\hline SANS & 256 & 2 & 0.008 & 0.02 & 0.008 & 0.001 \\
\hline Cs & 512 & 0.5 & 0.001 & 0.002 & 0.001 & 0.000 \\
\hline
\end{tabular}


In other instruments (especially SANS and CS), the use of scintillators may be considered for their adyantages in fabricating annular ring detector geometries.

\section{DATA CAPTURE ELECTRONICS}

The data capture electronics (DCE) must perform the function of a large multichannel analyzer. All neutrons detected are assigned a descriptor constructed from the detector and time information appropriate for that particular event. This descriptor then is used as an address for a read-increment-write operation on a large random access memory. This large memory, which is emptied at the start of a run, contains the complete record of the neutrons detected during the run. It is sometimes referred to as the run histogram.

In some cases, the descriptor will be coristructed from two time subdescriptors instead of the usual one. This occurs wherı time-dependent phenomeria are being studied. The two times are t, the time of arrival of the nautron measured from the time the protons hit the spallation target, and $p$, 7 period count measuring the time elapsed since the sample environment was changed.

The requirements of the DCE are listed below.

1. Record the neutron event by first registering the time of arrival. Because the neutron detection rates reach tens of megahertz in some cases (Table IV-I), it is important that the DCE should not introduce any excessive dead-time corrections $(d ! c)$. In ziny case, the highest dtc should not exceed $4 \%$ and in gereral should be well below $0.5 \%$.

2. The time of arrival is recorded as an $n$-bit time descriptor so that $2^{n} \geq n_{t}$ where $n_{t}$ is the maximum number of time channels required for a particular instrument. The values of $n_{1}$ are given in Table VI-I.

3. The time descriptor specifies the time channel where the event occurred. The time channels may have a constant width $\Delta t=c$, but provisions should be made to allow the user to choose a regime where the width of the time channels increases at longer times. For example, $\Delta t_{1}=c+a \cdot t_{i}$, where $c$ and a may be set by the user.

TABLE VI-I. Memory Requirements fo: Each Instrument

\begin{tabular}{lrrccc} 
Instrument & $\begin{array}{c}\text { Number of } \\
\text { Spectra } \\
n_{\mathrm{s}}\end{array}$ & $\mathrm{n}_{\mathrm{t}}$ & $\begin{array}{c}\text { Number megawords } \\
\text { in Run } \\
\text { Histrogram } \\
\left(n_{\mathrm{d}} \times \mathrm{n}_{\mathrm{f}} \text { )(bytes) }\right.\end{array}$ & $\begin{array}{c}\text { Word Size } \\
\text { (bytes) }\end{array}$ & $\begin{array}{c}\text { Memory } \\
\text { Size } \\
\text { (Megabytes) }\end{array}$ \\
\hline SCD & 12288 & 256 & 3 & 3 & 9 \\
FDS & 12 & 1000 & 0.01 & 3 & 0.03 \\
GPD (p) & 120 & 8000 & 1 & 3 & 3 \\
GPD (1) & 120 & 4000 & 0.5 & 3 & 1.5 \\
HRPD & 64 & 16000 & 1 & 2 & 2 \\
CQS & 128 & 2000 & 0.25 & 2 & 0.5 \\
BS & 128 & 4000 & 0.5 & 2 & 1 \\
SANS & 256 & 512 & 0.13 & 3 & 0.5 \\
CS & 128 & 4000 & 0.5 & 2 & 1 \\
\hline \hline
\end{tabular}


4. Construction of the final descriptor (D) may vary from instrument to instrument. In the simplest case all of the detectors (spectra) are recorded individually and the final descriptor consists of two parts. $D=n_{s}+n_{t}$ where $n_{s}=$ bits describing the spectrum, and $n_{t}=$ bits describing the time channel.

5. However, on some instruments it will be desirable to 'gang' detectors together. This reduces the rumber of spectra and hence the size of the run histogram. This may not affect the memory because it must be large enough to cope with the worst case, but it does affect all the subsequent storage and processing requirements (see Sec. VII). Ganging detectors also enables pseudo-detectors to be created that may be more physically useful than the individual detectors. For example, in Fig. VI-1 an area detector is shown with square cetector elements. If this detector were being used for diffraction, it could be very useful to gang the elements into the pattern shown corresponding to constant $2 \theta$ channels. A flexible ganging system is achieved best by using an indirect addressing mode technique. Instead of using the detector address as the detector subdescriptor, the contents of that address in a detector mapping table are used as the subdescriptor. The user should be able to load the detector mapping table by running a simple program and be able to realize any ganging scheme required.

6. After creating spectrum and time subdescriptors, the final descriptor may be constructed. A comipressed descriptor is useful when the total number of time channels is not equal to an integer power of two. In this case, a smailer histogram size is achieved if the descriptor $D$ is calculated from the expression $D=t+n_{t} s$, where $t=$ time subdescriptor, $s=$ spectrum subdescriptor, and $n_{1}=$ number of time channels used.

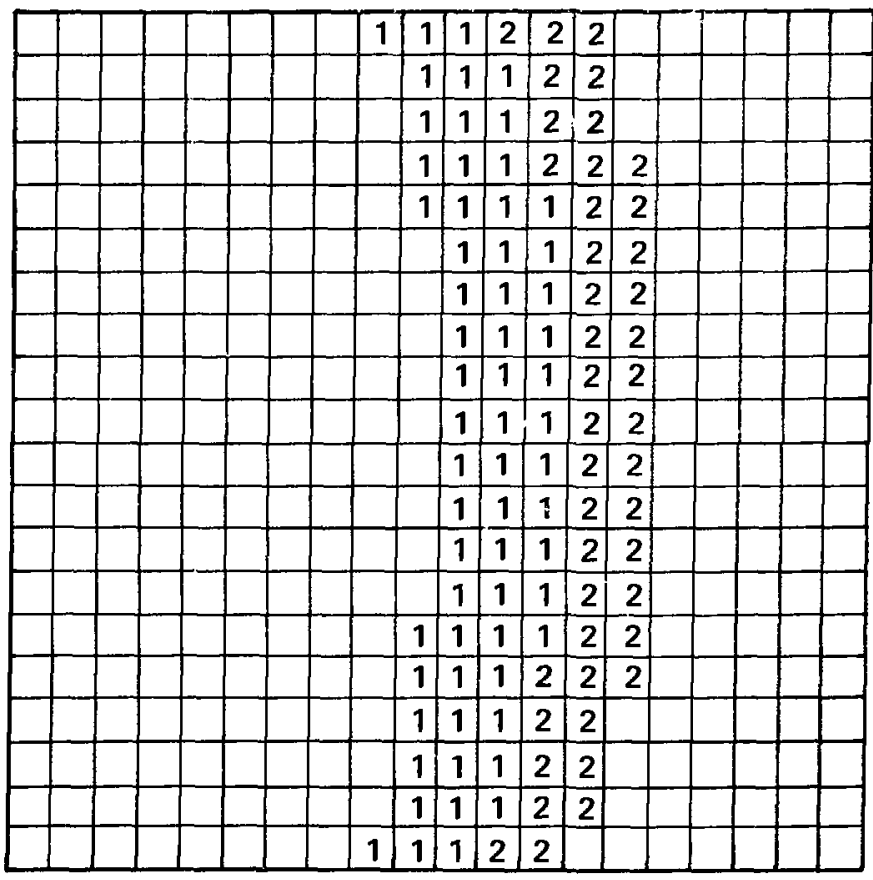

Fig. VI-1. A possible mapping scheme for the single crystal area detector gangs elements in constant-20 channels. 
7. In a similar way the perioa $p$ subdescriptor may be incorporated $D=t+n_{t} s+$ $n_{t} n_{s} p$.

8. Each DCE should contain its own large random access memory to contain the run histogram. The size of this memory (in words) is dictated by the length of the longest descriptor that might be reasonably used on a particular instrument. This is determined by the maximum number of spectrum and time channels that are required. These quantities are given in Table VI-I. The lengths of the words used in the memory are determined by the size of the count in each channel that will be required and by the method adopted in dealing with overflows. All counts must be accurately recorded and either the word length should be long enough to cope with the highest count required, or a mechanism must be used to store the overflow addresses. For low-count rate instruments a word length of 16 bits may be adequate. This permits a maximum count of $64 \mathrm{~K}$ before overflow occurs. For many instruments it may be inconvenient to work with the large number of overflows that would occur with a word length of 16 bits, and in these cases a word length of 24 bits has been sugges ed in Table VI-l.

9. The memory size (in Mbytes) for each instrument is given in Table VI-I. Note that for two of the instruments the size exceeds 2 Mbytes. A reduction in the memory size required by the GPD instrument (in powder use) could be achieved if the detectors were arranged on an isochronous surface (time focusing). The current proposals suggest that a resolution focused locus will be used that requires the detectors to be treated separately. The large memory size required by the SCD instrument may oniy be reduced by decreasing the number of area detectors to one or two. Even so, each area detector will require a megaword of DCE memory to store the run histogram.

\section{THE USER INTERFACE: REQUIREMENTS}

The user interface is the description of the data acquisition and control system as presented to a scientific user of the system. It includes the physical methods by which the user must interact with the system-the screens, plotters and keyboards-and of equal importance, the command language available to him to perform his tasks. Before attempting to specify the hardware/software interface, it is essential that the user's requirements be listed. These fall into two categories: requirements needed to successfully initiate, record, and file a run or series of runs (data taking); and those necessary to analyze the data. The division is important because the first is a real-time requirement that has a substantial penalty (in the form of an underused expensive resource) if it is not met.

\section{A. Data Taking}

In this section the user's requirements fall into three areas: initiating a run or sequence of runs after setting the appropriate parameters; displaying the results for the current and previously recorded runs; and filing and cataloguing the results.

Some requirements are common to all three categories. The user should be able to control an experiment using a concise set of keyboard instructions. It should be impossible for a user to issue commands to more than one instrument. The instructions should be self-checking to prevent the accidental use of an inappropriate 
command that could adversely affect the user's experiment. After a hardware failure and reloading of the control programs, the user should be able to return to the prefailure state without interrupting the operation of the DCE. A HELP command should be available that provides information to new users on how to use the system.

Before explaining the user's needs in more detail it is necessary to provide two definitions.

A run is the basic unit of data collection. It is a period of data acquisition with the detectors, sample position, and sample environment in a fixed state. Thus, during a run all parameters should stay constant. An example of a run mighi be:

Collect data with the time channels set to be $\Delta=t / 500, t_{1}=1000 \mu s, t_{2}=10000 \mu s$ from. an area detector with the sample in the orientation $\omega=20.1^{\circ}, \chi=2^{\circ}, \phi=10^{\circ}$. The sample temperature is $240 \pm 2 K$. Stop data collection when the monitor counts reads $10^{7}$.

If the temperature, timo channel width, or any other parameter is changed it is considered a separate rurı. Each run is identified by a run number.

The end-product of a successful run is a file containing a list of all the parameters that may be set to define a run, together with the time-of-flight spectra (the run histogram) recorded in the DCE memory. To be useful as a starting point for a data analysis sequence the file should contain all other parameters that might be needed. These parameters cannot be changed by the user (for example, the primary flight path $L_{1}$ or the detector angie) and therefcre are not unique to a particular run.

1. Initiating Runs: User Requirements. The user must be able to change parameters in the DCE or the sample environment by keyboard commands. Ideally the DCE parameters (for example, time channel widths or boundaries, detector mapping table, etc.) should only be changeable by keyboard commands to prevent any inadvertent change during a run. If panel switches must be used they should be computer readable. The user then starts a run or sequence of runs for a preset monitor or time count. When a sequence of runs is specified, it will involve DCE parameter changes or sample environment changes between runs. These should be implemented by a stored list of commands. The user should be able to stop or pause/restart runs at any time, even interrupting a predefined run sequence.

2. Display: User Requirements. It is extremely important that the user is provided with a fast, versatile, and physically meaningful method of displaying spectra from the run currently being collected or runs recently completed.

The graphics screen display should enable arbitary choices of the $x, y$ scale sizes and their origins, linear and logarithmic plots, and the simultaneous display of two or more spectra (not necessarily from the same run). In particular, the user should be able to select physically meaningful scales such as the lattice spacing $d$, momentum transfer $Q$, energy transfer $E$, etc.

The display command language should permit the user to perform simple arithmetic operations on a run or group of runs. For example, it should be possible to display the spectrum $c$, where $c^{i}=\left(a R_{1}^{i}-b R_{2}^{\prime}\right) / c R_{3}^{i}, c^{i}=i$-th element of spectrum $c, R_{1}, R_{2}, R_{3}$ are separate runs, and $a, b, c$ are constants chosen by the user.

It should be possible to produce a hard copy of anything aisplayed on the screen. This hard copy should have a moderate quality and be froduced within a few seconds. 
Because the display of current or recently completed runs is a very frequently used function, the methods of switching from one spectrum to another and changing scales should be made as simple as possible. For example, the user should be able to display the entire spectrum for a particular detector (or group of detectors) and then zoom-in on a particular region of interest by using the $x-y$ cursor or simple keyboard commands to define the new scale limits.

When area detectors are used it will be necessary to display intensity maps of a particular plane or projection of the $x, y, t$ space. These may be represented on a conventional screen by two-dimensional histograms or contour maps. The data would be more clearly represented by the use of a display using gray scales or color.

The requirement that current and recently recorded spectra should be displayed quickly, within five seconds, is paramount. Table VII-I lists the storage location of the system for displaying data files as a function of their ages. In this table 'current' means the run currently being collected or the last recorded run.

'Attached' is a category of files that have been marked for immediate display and must be stored locally.

3. Filing and Cataloguing. Upon completion all runs should be filed without the experimentalist's intervention. This may occur when the preset monitor or time count is reached, or when a run is ended prematurely by a user command. This copy of the run, the primary file, will be used for local display up to 48 hours after the run has been recorded.

Users should be able to make a file copy of the current run in progress by use of a single command.

\begin{tabular}{|c|c|c|}
\hline Age & Storage Location & Number of Files ${ }^{\mathrm{a}}$ \\
\hline 'Current' & $\begin{array}{l}\text { local disc } \\
30 \text { Mbytes }\end{array}$ & 1 \\
\hline 'Attached' & $\begin{array}{l}\text { loral disc } \\
30 \text { Mbytes }\end{array}$ & 20 \\
\hline $48 \mathrm{hr}$. & $\begin{array}{l}\text { hub disc } \\
500 \text { Mbytes }\end{array}$ & 40 \\
\hline 7 days & $\begin{array}{l}\text { hub disc } \\
500 \text { Mbytes }\end{array}$ & 100 \\
\hline 30 days & $\begin{array}{l}\text { archive medium } \\
\text { locally stored }\end{array}$ & 500 \\
\hline $1 \mathrm{yr}$ & $\begin{array}{l}\text { archive medium } \\
\text { warehoused }\end{array}$ & 5000 \\
\hline
\end{tabular}

Both the number of files and their : ize will vary from instrument to instrument. See Table VII-ll for an estimate of the number of files per day for each instrument. 
Provision should be made for users to archive the run as soon as a primary file has been created. The archive copy should be on a physically different medium from the primary file and after 48 hours the archive copy should be duplicated to provide two long term copies of the data. The archiving process should be an extremely simple command to permit the archiving of multiple runs. The user should not be required to mount tapes or in other ways involve himself with computer hardware.

The deletion of primary runs should be the responsibility of the user. A warning message and a further user response should be required for the deletion of runs not previously archived.

To ensure that the system has sufficient space for the creation of primary files, users should be warned if insufficient space is available when a new run is started. The space required to start a run should be stated. The user should be able to easily determine the amount of local storagi? space available and be able to list quickly the primary and attached files and theil sizes su that they could be archived and/or deleted.

A catalogue of the last 5000 runs performed on the instrument should be immediately available (within 25 seconds) on a screen or hard copy terminal. The form of the catalogue should be a single line entry for each run. The line should be 60 characters long to print/display on a variety of terminals. It should contain the following information.
run no. extension
date
time
state
user
(2) (attached, archived)
title
size
run duration
type of dump
(1) (intermediate cr final)

Runs that were deleted before archival should not be included. Users should be able to invoke simple commands that would display subsets of the catalogue. For example, a user should be able to recall all runs performed by a particular user, runs between given dates, or runs containing a particular character string within the title.

To judge the amount of file storage capacity that will be required both locally and in the archival system, it is necessary to know both the size of the data files and the frequency with which they are produced. These estimated figures shown in Table VII-II furnish the required information for calculating traffic expected on the computer network.

\section{B. Data Analysis}

Data analysis consists of two problems, that of providing an immediate display of physically meaningful spectra (S(Q) vs. $Q$, etc.) to the user while a run is in progress, and the larger computational problem of reducing the entire run histogram to a form suitable for comparison with theory or for the least-squares refinement of structural models. 
TABLE VII-II. Estimates of Daily Storage Requirements

\begin{tabular}{cccc}
\hline & & $\begin{array}{c}\text { Run } \\
\text { Histogram }\end{array}$ \\
Instrument & Runs/Day & Size (Megawords) & Migawords/Day \\
\hline SCD & 10 & 3 & $30^{\mathrm{a}}$ \\
FDS & 10 & 0.01 & 0.1 \\
GPD & 20 & 1 & 20 \\
HRPD & 10 & 1 & 10 \\
COS & 2 & 0.25 & 0.5 \\
BS & 2 & 0.5 & 1 \\
SANS & 10 & 0.13 & 1.3 \\
CS & 2 & 0.5 & 1 \\
\hline
\end{tabular}

1. Immediate Display. The requirement for Immediate display has already been mentioned under the display function. In this section we attempt to quantify the amount of input/output (I/O) and central processing unit (CPU) power required.

The programs that provide immedisie displays during data collection should be capable of transforming and displaying a single time-of-flight spectrum in a few seconds. Two dimensicnal data, consisting of many individual spectra, may take a few tens of seconds.

The data transformations will typically require (for single spectrum) the copying of 3 spectra to memory, about 10 floating point operations per data point, and the output of the transformed file.

A single spectrum typically contains a few thousand data points. !n the case of twodimensional data roughly 20 times as many data points may be involved.

2. Bulk Data Analysis. Although the final analysis of the data from different instruments varies considerably, there is a common problem that may be quantified. There is a need to remove the instrument dependent characteristics such as background spectrum, energy dependent incident beam intensity; and the detector response.

The computational size of this problem may be estimated from the size of the run histograms, the frequency at which runs are recorded, and the amount of processing required per histogram element.

These quantities are estimated in Table VII-III. Benchmark tests may be employed to convert the figures in Table VII-III to specific hardware requirements.

The rest of the bulk data analysis problem is difficult to quantify, but experience suggests that this activity requires a machine with a power of approximately 1.0 MIPS (1 MIP $=10^{8}$ instructions/second) or the proportional share of a larger machine. 
TABLE VII-III. Parameters Indicating Daily Computational Needs of Each Instrument

\begin{tabular}{ccccc} 
Instrument & $\begin{array}{c}\text { Run Size } \\
\text { Megawords }\end{array}$ & $\begin{array}{c}\text { Run Frequency } \\
\text { Runs/Day }\end{array}$ & $\begin{array}{c}\text { I/O } \\
\text { Megawords/Day }\end{array}$ & $\begin{array}{c}\text { CPU } \\
\text { MFLOPS/Day }\end{array}$ \\
\hline SCD & 3 & 10 & & \\
FDS & 0.01 & 10 &.-- & 1 \\
GPD & 1 & 20 & 0.5 & 200 \\
HRPD & 1 & 10 & 80 & 100 \\
COS & 0.25 & 2 & 40 & 5 \\
BS & 0.5 & 2 & 2 & 10 \\
SANS & 0.13 & 10 & 4 & 15 \\
CS & 0.5 & 2 & 6 & 10 \\
\hline
\end{tabular}

${ }^{\text {a MFLOPS }}=$ million floating point operations.

\section{THE USER INTERFACE: HARDWARE}

To control and interpret a series of runs on a particular instrument, the user should have exclusive use of the following configuration. A medium sized ( 0.25 MIPS) minicomputer with a hardware floating point unit containing 0.25 Mbytes of memory should be available for user or display programs. The peripherals should include a hard copy alphanumeric terminal, a graphics display screen (with or without a separate keyboard), disc file space, 5 Mbytes for program development, and 20-50 Mbytes for run file storage. Five Mbytes should be allowed for storage of standaru control and display programs, a parallel interface to the DCE, and communications iriterfaces to shared resources should be available.

He should have shared use of a lineprinter $(600 \mathrm{lpm})$, a hard copy graphics device, and a file archiving system for both data and programs. The user should have access to a more powerful computer ( 1 MIPS) for bulk data processing and model fitting. There should be adequate hardware and software links between these two computers to enable data and program files to move easily between them.

The hard copy terminal is necessary to provide a record of the course of the run. It will $\log$ instructions issued and any fault condition messages. It can be siow (30 characters/second) and inexpensive.

The graphics screen should have a resolution of at least $1000(x)$ by $500(y)$, and it should provicie a display area of at least $12 \mathrm{in.} \mathrm{(high)} \mathrm{by} 14 \mathrm{in.}$ (wide). The size of the screen is especially important for displaying three-dimensional information, and the increased use of area detectors or pulsed sources will make this a common requirement. Either a storage tube or a refresh display could be used, although the latter would provide a greater flexibility in use. The screen should be capable of drawing a single spectrum (1000-4000 points) in 2-3 seconds. On those instruments with area detectors it would be advantageous to have a screen with a gray scale capability. This enables an intensity map of the detector to be easily displayed.

The screen should be equipped with a crosshair graphics cursor controllable from a joystick (or similar device) preferably with two-speed operation. The cursor is essential for fast interaction with the graphics display. This includes finding peak positions, calculating background levels and peak heights, identifying areas to be redrawn on a larger scale, and marking areas over which a spectrum integral is displayed. 
The minicomputer will be used to provide the normal graphics display facilities previously outlined in Sec. VII. It is likely that some users will develop their own display and/or analysis programs, and for this reason a certain amount of disc space (5 Mbytes) should be available for this purpose. This will be in addition to the larger volume of file space (20-50 Mbytes) reserved for run data files. The size of disc space to be provided locally may be estimated from Tables VII-I and VII-II.

The communications link from the minicomputer to the file archiving system is very important. The number and size of the rur.s is ho archived may be estimated from Table VII-II.

The line printer, hard copy graphica! Jutput, and archiving file store are expensive items that should be shared.

The hard copy graphics device should have a similar resolution to the screens. It should be capable of reproducing any picture from a screen display, preferably by the simple operation of a 'hard copy' command. It should be fast enough to produce a 10 - by 8 -in. copy in a few seconds.

\section{THE USER INTERFACE: SOFTWARE}

The users will control the course of the experiment by a command driven dialogue that will provide both the control and display functions. This command language must be logical and concise with consistent argument or parameter form to be quickly learned and correctly used by new users.

Outlines of the commands that might be used for both the control and display functions are given in Sec. IX-A and Sec. IX-B.

In addition to this supplied software however, the user should have at his disposal the facilities of a modern operating system and utility programs for the development of his own display or analysis programs.

It is also important that a common file structure and naming convention be adopted for filing the completed runs. This is discussed in Sec. IX-C.

\section{A. The Control Commands}

Because certain sequences of commands are either nonsense for example, stopping a run before it has started) or ilkely to lead to :aulty data taking (for example, changing the time channel width during a run), they must be prevented. This is achieved most easily by considering the instrument to be in one of a number of 'states.' and while in a particular state only a restricted set of commands may be used.

Examination shows that there are only three permissible states of an instrument.

SETUP_data are not being taken; DCE or sample environment parameters may be set in preparation for a run.

RUN_data are being taken (unless hardware inhibits are in effect); parameters may not be changed.

HALT--data are not being ta'sen, and parameters may not be changed. (This is a temporary pause condition.)

These arise from the fact that there are four fundamental states (data taking on or off combined with parameters changeable or fixed) of which one, changing while taking data, is forbidden. 
All possible movements between these three states may be achieved by four commands. These are illustrated in Fig. IX-1. Thus, when in a SETUP state only the BEGIN transition command may be issued. The effects of the four transition commands are given in Table IX-I.

In addition to the four transition commands, three other commands are necessary, SET, DUMP, and DISPLAY. The meaning of these commands are given in Table IX-II. The first two are input/output commands, the third is a command that removes the us ar from control mode to display mode where a set of display commands are available.

Thus, the seven commands

$\begin{array}{ll}\text { BEGIN } & \text { S } \\ \text { END } & R H \\ \text { PAUSE } & R \\ \text { CONTINUE } & H \\ \text { SET } & S \\ \text { DUMP } & \text { RH } \\ \text { DISPLAY } & \text { SRH }\end{array}$

are the control commands. The instrument states, SETUP (S), RUN(R), and HALT(H), in which they may be used as shown by the letters following the command.

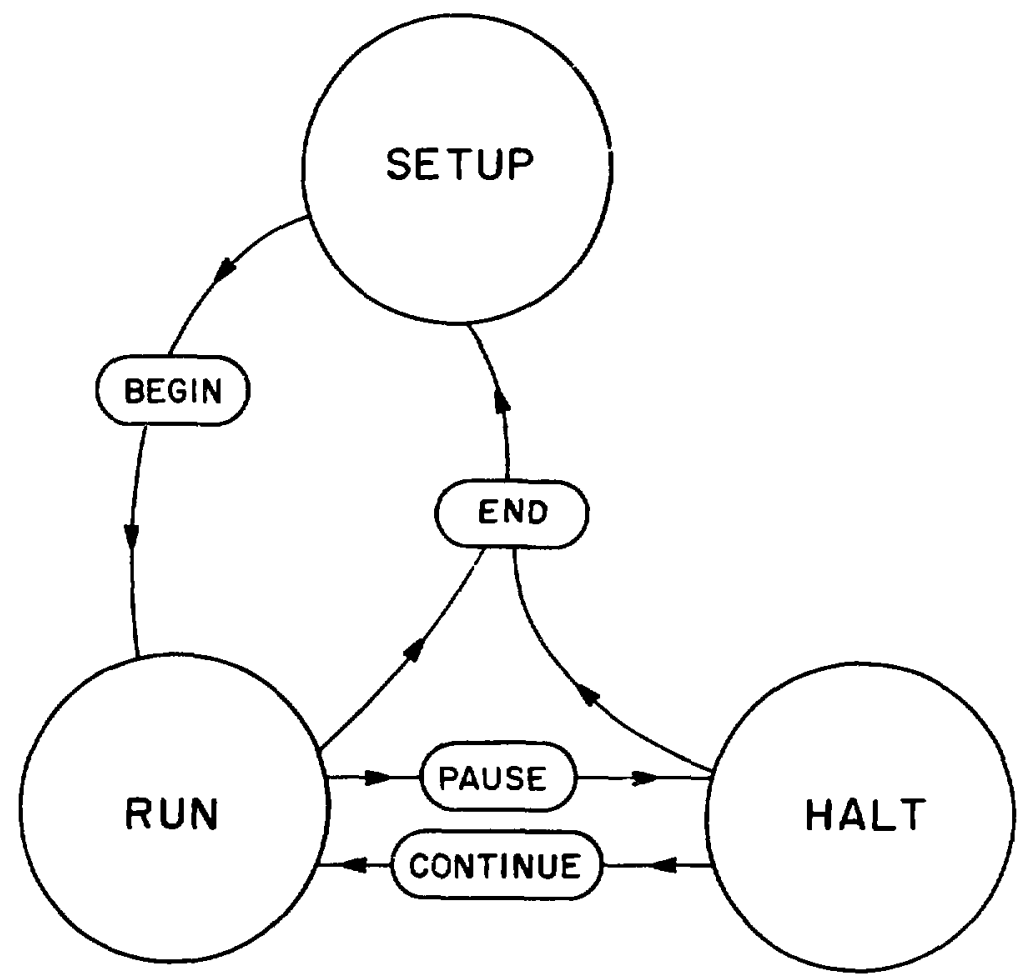

Fig. IX-1. The three states of data acquisition with the transition commands. 
TABLE IX-I. Transition Commands and Their Effects

Command Effects

BEGIN Issues a new run number. Asks the user to type in the run title. Uses all of the information stored in the run control file (RCF) to set the necessary parameters in the DCE. Checks for possible inconsistencies between parameters and reports errors. Clears the run histogram memory in the DCE. Initializes the clock or monitor scalers that provide the intermediate dump interrupt. Removes inhibit from data collection. Sets flag in RCF to run state. Informs user of new state. When the run duration scaler limit has been reached an END command is automatically executed.

END Inhibits data collection. Creates a run data file (RDF) from parameters stored in the RCF and the run histogram in the DCE. Copies the RDF to local disc storage. Sets flag in the RCF to SETUP state. Informs user of new state.

PAUSE Inhibits data collection. Sets flag RCF to HALT state. Informs user.

CONTINUE Removes inhibit from data collection. Sets RCF flag to RUN state. Informs user.

TABLE IX-II. Additional Commands Necessary for Data Acquisition

Command Argument Effect

SET Parameter/ values
DUMP

DISPLAY
Change the value of a parameter in the DCE, sample environment or RCF (a file containing the title, run, number, dump interval, duration, etc., of the next run to be started.).

When a parameter is changed in the DCE, a return should be made atter this has been completed.

When a sample environment parameter is changed (for example; $\theta, \mathbf{T}$ ), a return should be made when the information has been received by the control system-not when the physical parameter has been changed. Hardware inhibits should be used to halt data collection of any sample environment parameters are beyond limits.

A SET command without agrument should display the parameters and their current value.

It should be possible to input values from files.

A command that takes the current contents of the run histogram, DCE parameters, and creates a new RDF on local disc storage. A new run extension number is chosen.

Moves the user to display mode. 
The commands should be self-checking. A record of the current state of the instrument should be kept and checked against the commands as they are issued. Invalid commands should result in an error message to the user. Automatic checks should be made on the values issued by SET commands. A record should be kept of the limits between which a given parameter may be set, and the command checked against these values. These control commands may be issued from the keyboard or they may be read from a control instruction file (CIF). To initiate reading from a CIF one further instruction is required, OBEY filename. On receipt of an OBEY command, the file specified is used as the source of commands. Each command is acted upon in turn until a BEGIN command is reached. This is acted upon, but control reverts to the keyboard until the run has completed (to allow for manual END, PAUSE, DUMP, or DISPLAY commands). At the end of a run, control reverts to the CIF until the next BEGIN is encountered, and so on. When the last instruction has been read from the CIF file, control reverts to the keyboard.

\section{B. The Display Commands}

As mentioned in Table IX-II the use of the DISPLAY command should remove the user from control mode and take him into display mode. In this mode a set of commands will provide the type of display functions outlined in Sec. VI!.

These cover three main areas; the graphical display of a single spectrum or multiple spectra; the alphanumeric display of parameters, either DCE, or run control file information for the current run or from the parameter block of a completed run; and the display of the catalogues of recorded runs. Because it will be necessary to archive or delete runs after consulting this catalogue, these commands (ARCH, DELETE) should be within the display level.

The types of commands that might be used for line spectrum displays, for example, are given in Table IX-III. The values of all parameters that may be set by a command, (for example, spectium number, run number, axis units, axis minimum and maximum, summed zone) should be stored in a display information table. These values should be used as the defaults in all display operations. Changing any of the values should result in a redrawing of the display (except in the case of AS).

When it is required to display arithmetic combinations of runs, first combine the runs in a scratch file by using a series of commands like those illustrated in Table IXIV. The scratch file would be used as input to the display commands NS or AS. Frequently required manipulations, such as $c=\left(s_{i} r_{1} / m_{1}-s_{i} r_{2} / m_{2}\right)$ a, where $s_{1} r_{1}, s_{i} r_{2}$ = spectrum $i$ of run 1 and $2, m_{1}, m_{2}=$ monitor spectrum run (1,2), and $a=$ constant, could have a single command. 
TABLE IX-III. Examples of Spectrum Display Commands

\begin{tabular}{|c|c|c|}
\hline Command & Argument & Effect \\
\hline NS & $\begin{array}{l}\text { spectrum/ } \\
\text { run number }\end{array}$ & $\begin{array}{l}\text { New spectrum. Draws a single spectrum with the default } \\
\text { values of } x \text { and } y \text { stored from previous run. }\end{array}$ \\
\hline AS & $\begin{array}{l}\text { spectrum/ } \\
\text { run number }\end{array}$ & Add spectrum. Adds a single spectrum to the current display. \\
\hline $\mathbf{N}$ & -- & $\begin{array}{l}\text { Next. Like NS but draws the spectrum following the } \\
\text { previously drawn spectrum. }\end{array}$ \\
\hline AN & --- & $\begin{array}{l}\text { Add Next. Add next spectrum to current display and display } \\
\text { sum. }\end{array}$ \\
\hline $\mathbf{C A}$ & axis/mode & $\begin{array}{l}\text { Change Axis. This command enables the user to change the } \\
\text { units of a particular axis. The unit picture is redrawn with the } \\
\text { new axes. }\end{array}$ \\
\hline SC & $\begin{array}{l}x-\min , x-\max \\
y-\min , y-\max \end{array}$ & $\begin{array}{l}\text { Scale change. By specifying } c \text { for } x \text {-min the cursor is dis- } \\
\text { played and may be used to define the new limits. }\end{array}$ \\
\hline IN & $x_{1}, x_{2}$ & $\begin{array}{l}\text { Display the integral between limits. By specifying } c \text { for } x_{1} \\
\text { display cursor and use to define } x_{1}, x_{2} \text {. }\end{array}$ \\
\hline CON & $-\cdots$ & Leave display mode and return to the control mode. \\
\hline Cu & $\cdots$ & Display cursor and use it to print $x, y$ position chosen. \\
\hline
\end{tabular}

TABLE IX-IV. Arithmetic Commands in Display Mode

\begin{tabular}{|c|c|c|}
\hline Command & Argument & Effect \\
\hline ADD & $\begin{array}{l}\text { run } 1, \text { run } 2 \\
\text { or } \\
\text { run } 1 \rightarrow \text { run2 }\end{array}$ & $\begin{array}{l}\text { Adds all spectra of the runs specified. run } 1 \rightarrow \text { run } 2 \\
\text { implies all runs from run } 1 \text { to run } 2 \text { inclusive. } \\
\text { Store in a scratch file, display scratch file } \\
\text { name used. }\end{array}$ \\
\hline SUB & run 1 , run 2 & Subtract run 2 froin run 1. \\
\hline DIV & run 1, run 2 & Divide run 1 by run 2. \\
\hline MUL & run 1, run 2 & Multiply run 1 by run 2 . \\
\hline SCA & $\begin{array}{l}\text { p, run } 1, \\
\text { run } 2 \text { or } \\
\text { run } 1 \rightarrow \text { run } 2\end{array}$ & Multiply all of the runs listed by the value p. \\
\hline
\end{tabular}




\section{The Format of the RDF}

The RDF Sec. VII, should contain all information necessary for subsequent data analysis. Its structure should be the same for all instruments, to enable standard reading routines to be used in different data analysis or display programs. A possible structure for the RDF is shown in Fig. IX-2.

The abstract is used to identify the file and should contain the following information.

$\begin{array}{lr}\text { Instrument } & 4 \\ \text { Run no. } & 6 \\ \text { Run no. extension } & 3 \\ \text { Duration } & 5 \\ \text { Time } & 6 \\ \text { Date } & 6 \\ \text { User } & 8 \\ \text { File type } & 2 \\ \text { Title } & 25\end{array}$

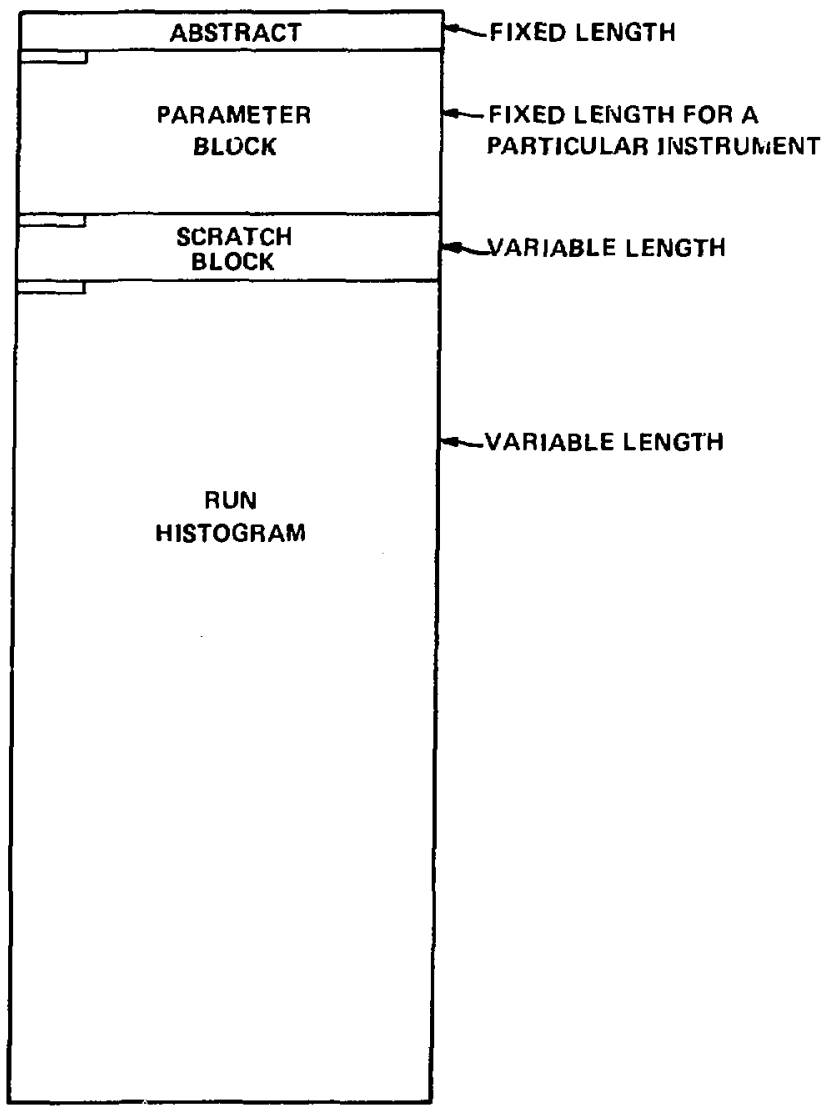

Fig. IX-2. Format of the RDF. 
The figures denote the number of characters that might be used for each field. The abstract will have the same format for all instruments. The parameter block is a large but fixed length block that records all of the parameters necessary for subsequent data analysis. Most importantly, this block will contain those parameters that may be varied from run to run (for example, time channel width, rotor period, detector ganging arrangements). It should also contain those parameters that change infrequently $\left(L_{1}\right.$, $L_{2}$, .. etc.), but that are vital for display programs or subsequent data analysis. The parameter block is fixed in the sense that it is of a fixed length for a particular instrument, but may vary among instruments. For this reason its length is included as the first parameter.

The scratch block is simply a free area for the user to record any notes or parameters.

The run histogram is the copy of the spectrum stored in the DCE. It will be of variable length depending on the number of time/spectrum channels chosen. It should contain the data in spectrum order. If time-dependent effects have been studied, all of the spectra for one time domain should be grouped together.

Finally, the RDF file name should be carefully chosen to be as meaningful as possible. It should begin with a one or two letter instrument code and include the run number and run number extension.

Run data files may be produced in one of four ways: on completion of a run, either by an END command, by the run duration scaler reaching its preset limit, by a DUMP command, or by an automatic, intermediate dump. This last provision is important. If it is not possible to inhibit data collection when the sample environment changes, it is necessary to take intermediate records of the run. This could be achieved by providing a second preset scaler, the dump scaler. On reaching its preset value the DCE would produce a dump interrupt, causing a DUMP command to be issued without user intervention. The dump scaler would then be reset at its previous value and the run continued.

\section{TIME SCALES}

We have summarized the stages necessary to realize a complete data acquisition and analysis system by early 1985 in Fig. X-1. This illustrates that many man years of effort are involved and that decisions are required very quickly regarding the funding and implementation of the project. Many of the time scales suggested are far too short, especially with regard to the design of the high-speed electronics.

\section{ACKNOWLEDGMENTS}

M. W. Johnson wishes to thank R. N. Silver for an opportunity to visit the WNR at the Los Alamos National Laboratory. M. W. Johnson also acknowledges the warm rersation extended to him by Group P-8 personnel and is grateful for the useful discussions with Jung P. Hong. 
1. FUNCTIONAL REQUIREMENTS (DRAFT)

2. DESIGN CONCEPT

3. FUNCTIONAL REQUIHEMENTS (FINAL)

4. SYSTEM DESIGN

5. PAOJECT PLAN

B. HIGH SPEED ELECTRONICS

SPECIFICATIONS

DETAIL DESIGN

PAOTOTYPE

FABAICATION

INTEGRATION

1. COMPUTER SYSTEM

SPECIFICATIONS

REQUEST FOR QUDTATION

PURCHASE ORDER

DELIVERY

INTEGRATION

8. SOFTWARE

SPECIFICATIONS

OESIGN (MOCK.UPS)

IMPLEMENTATION

INTEGRATION

9. SOFTWARE IAPPLICATIONS|

SPECIFICATIONS

OESIGN

IMPLE MENTATION

INTEGRATION

10. SYSTEM INTEGRATION

PROJECT SCHEDULE

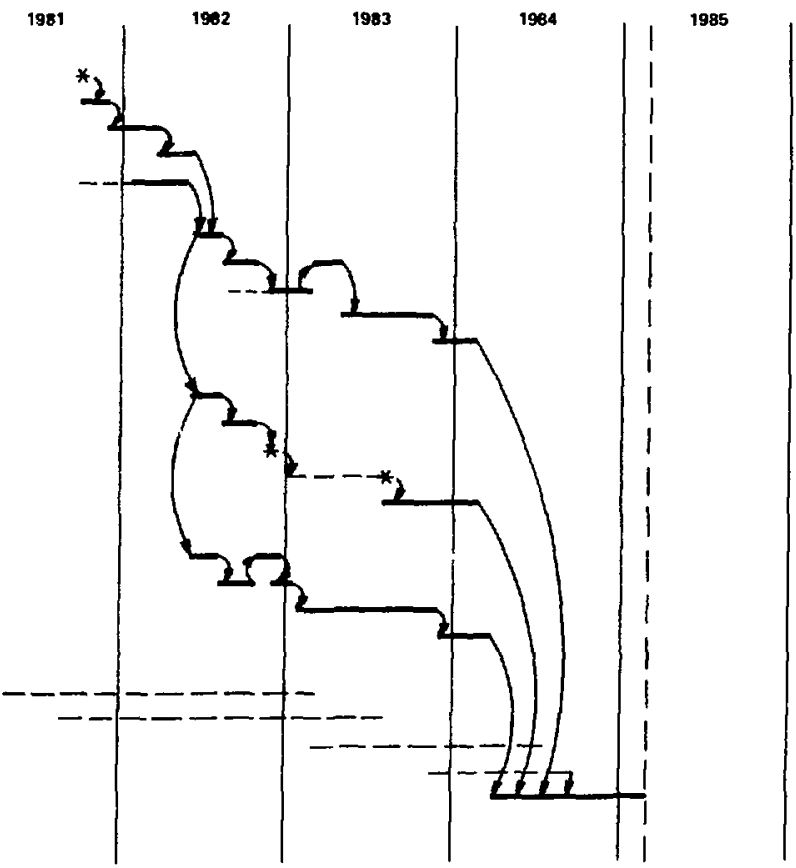

Fig. X-1. Stages and time schedule necessary to complete data acquisition and analysis systems are diagrammed.

\section{REFERENCES}

1. George P. Lawrence, Richard K. Cooper, Daniel W. Hudgings, George Spalek, Andrew J. Jason, Edward F. Higgins, and Robert E. Gillis, "LASL High-Current Proton Storage Ring," Proc. XIth International Conference on High Energy ACcelerators, Geneva (Berkhauser Verlag, Basil, Switzerland/Boston, 1980), p. 103.

2. R. N. Silver, "Planning for WNR/PSR in 1986," Internal Memorandum P-8-81-227, August 12, 1981.

3. H. Jacobe, B. Meardon, and R. Stewart, Institut Laue-Langevin report 74 Mi 67T, Grenoble, France. 